\title{
Regulatory Effects of Nitric Oxide on Reproduction and Melanin Biosynthesis in Onion Pathogenic Fungus Stemphylium Eturmiunum
}

\author{
Yanxia Zhao \\ Jiangsu Normal University \\ Wenwen Yuan \\ Jiangsu Normal University \\ Mengni Sun \\ Jiangsu Normal University \\ Xiuguo Zhang \\ Shandong Agricultural University \\ Weifa Zheng ( $\nabla$ yyzw@jsnu.edu.cn ) \\ Jiangsu Normal University
}

Research

Keywords: pseudothecia, conidia, sodium nitroprusside, polyketide synthase, tyrosinase

Posted Date: September 9th, 2020

DOl: https://doi.org/10.21203/rs.3.rs-74238/v1

License: (9) This work is licensed under a Creative Commons Attribution 4.0 International License.

Read Full License

Version of Record: A version of this preprint was published at Fungal Biology on July 1st, 2021. See the published version at https://doi.org/10.1016/j.funbio.2021.01.010. 


\section{Abstract}

The formation of propagules (conidia and ascospores) is the critical stage for the transmission of the pathogenic fungus Stemphylium eturmiunum. However, how the development of these propagules is regulated remains to be fully understood. Here, we show that nitric oxide (NO) is necessary for the formation of conidia and pseudothecia in S. eturmiunum. Application of NO scavenger carboxy-CPTIO (cPTIO) or soluble guanylate cyclase (sGC) inhibitor NS2028 abolishes the formation of conidia and pseudothecia. In the culture of $S$. eturmiunum, supplement of NO-releasing compound sodium nitroprusside (SNP) results in an increased formation of conidia at $0.2 \mathrm{mmol} / \mathrm{L}$, and pseudothecia at 2 $\mathrm{mmol} / \mathrm{L}$. SNP supplement also triggered increased biosynthesis of melanin, which can be inhibited partially upon the addition of either arbutin or tricyclazole, the specific inhibitors for 3,4dihydroxyphenylalanine (DOPA) and dihydroxynaphthalene (DHN) synthetic pathway, respectively. Intriguingly, enhanced melanin biosynthesis triggered an increased formation of propagules; while its inhibition impaired their formation. The SNP-induced increment in the formation of propagules can be also compromised upon supplement of CPTIO or NS-2028. RT-PCR analysis showed that SNP at 0.2 $\mathrm{mmol} / \mathrm{L}$ promoted transcription of the genes encoding the conidiation co-regulators $b r I A, a b A$, and wetA, and inhibited at $2 \mathrm{mmol} / \mathrm{L}$. In contrast, application of SNP at $2 \mathrm{mmol} / \mathrm{L}$ increased transcription of the genes encoding mat1, and mat2, the genes related to sexual reproduction, and the transcription of two DNH melanin synthetic genes $p k s 1$ and $p k s 2$, and the key gene tyrfor DOPA melanin biosynthesis. However, the increased transcription of these genes is down-regulated or blocked upon supplement of cPTIO or NS-2028. Thus, NO regulates asexual and sexual development, as well as melanin synthesis in $S$. eturmiunum possibly through NO-sGC-GMP signaling pathway.

\section{Introduction}

The foliar fungal pathogen Stemphylium eturmiunum is a homothallic filamentous ascomycete causing severe leaf blight of onions (Fernandez and Rivera-vargas 2008). In addition, S. eturmiunum is also a postharvest spoiler of fresh tomatoes (Andersen and Frisvad 2004; Trinetta et al. 2013). The infection at the lesions of fresh tomatoes by the fungus results in the production of toxic metabolites infectopyrone and macrosporin (Andersen and Frisvad 2004). In natural habitats, S. eturmiunum develops asexual conidiophores for conidiation, and sexual fruiting bodies pseudothecia for producing ascospore (Simmons 2001). The conidia that easily reach the host alveola are the major infective propagules (Muñiz-Paredes et al. 2017). Notably, the conidial cell wall, directly in contact with host cells, consists of melanins in addition to the presence of a-(1,3)-glucan and proteinaceous rodlets. The fungal melanins, synthesized via DOPA or DNH pathway (Chang et al. 2019) both possess the potential to scavenge free radicals (Pacelli et al. 2020). In filamentous fungi, the presence of melanins in conidial cell wall confers the resistance to the attack of free radicals from host organisms, which, in turn, increases their pathogenicity for effective infection and transmission (Chamilos and Carvalho 2020; Amin et al. 2014; Cunha et al. 2010). The sexual fruiting body of fungi was constructed by tightly interwoven melanincontained hyphae (Engh et al. 2007). Similar to conidia, the unique structure of pseudothecia also 
confers fungi the capacity to survive in harsh environment (Lambou et al. 2008; Zhao et al. 2017). Thus, the involvements of melanin in the construction of conidia and pseudothecia endow the resistance of fungi against environmental insults and the effective infection and transmission (Pal et al. 2014).

Asexual sporulation is the most common mode for reproduction and transmission in filamentous fungi (Park et al. 2012) and is timed and genetically programmed (Adams et al. 1998; Lee et al. 2010). In Aspergillus, the conidial sporulation is determined by a central regulatory pathway, where the transcriptional factors $b r l A$, $a b a A$, wetA coordinate conidiation-specific gene expression and determines the order of gene activation during the formation of conidiophores and maturation of conidia (Boylan et a., 1987; Mirabito et al. 1989).

Similar to asexual sporulation, the formation of pseudothecia is also regulated by multiple genes. Previously, we showed that the development of pseudothecia in S. eturmiunum is regulated not only by the genes encoding MAT1, MAT2, and the protein in G-protein signaling pathway but also by magl, the gene responsible for the synthesis of arachidonic acid (Zhao et al. 2019). Treatment of $S$. eturmiunum with 5-azacytidine (5-AC) resulted in the complete silence of mag/ followed by disruption in the development of pseudothecia and melanin synthesis. Interestingly, the impaired development of pseudothecia can be restored by external supplement of arachidonic acid (Zhao et al. 2019), which implicates the significance of arachidonic acid, the common source for the genesis of oxylipins (Aukema et al. 2016), in sexual development of $S$. eturmiunum.

The successful survival of fungi in nature depends on the efficient communication with their surroundings (Hassan et al. 2019). In filamentous fungi, the communication with habitats is achieved by complex signaling systems that determine the fungal proliferation, development, and in some cases virulence (Kozubowski et al. 2009). The well-known signaling pathways in fungi include the protein kinase A/cyclic AMP (cAMP), protein kinase G/cyclic GMP (cGMP), protein kinase $C$ (PKC)/mitogenactivated protein kinase (MAPK), lipid signaling cascades, and the calcium-calcineurin signaling pathway (Kozubowski et al. 2009). PKG/cGMP pathway, which seems to exist in filamentous fungi, is activated by free radical molecule NO (Zhao et al. 2020). The NO, highly diffusible within the cell or through cell membrane (Lancaster 1997), can work as a transient, local, intra- or intercellular signaling molecule in miscellaneous biological systems including fungi (Culotta and Koshland 1992). In fungi, NO signaling is involved in conidiation, formation of sexual fruiting bodies, and regulation of secondary metabolism (Zhao et al. 2020). Established evidences have shown that NO can function as the activator of sGC able to bind selectively with the hemoprotein in SGC even in the presence of oxygen (Boon and Marletta 2005). The binding of $\mathrm{NO}$ with Heme iron triggers the change $\mathrm{SGC}$ conformation and subsequently activates its catalytic domain, where GTP can be catalyzed to cyclic GMP (cGMP) (Friebe and Koesling 2003). The produced cGMP then combines with PKG, which constitutes central downstream mediator of NO-cGMPPKG signaling pathway, and orchestrates pathway-specific cellular response through the phosphorylation of phosphorylation-dependent transcriptional factors (Contestabile 2008). 
Studies in the past decades have shown that NO-mediated signaling networks are involved in conidiation (Wang and Higgins 2005; Gong et al. 2007), the formation of parasitic structure of appressoria (Prats et al. 2008), asexual structures of sporangiophores (Maier et al. 2001), and sexual structures of cleistothecia in Aspergillus species (Baidya et al. 2011). In our previous attempts to unravel the regulatory mechanisms for sexual development of $S$. eturmiunum, we found that treatment of the fungus with 5-AC resulted in the formation albinism phenotype and the silence of the genes responsible for melanins synthesis in addition to magl. Application of SNP partially restored biosynthesis of melanins in 5-AC treated $S$. eturmiunum. Intriguingly, SNP supplement in non-treated $S$. eturmiunum increased the number of conidia and pseudothecia. However, how NO signaling affects asexual and sexual development remains to be established. In this study, we used SNP as the external NO source to probe the regulatory effects of NO on conidiation, sexual fruiting body formation, and production of melanin. Our data showed that NO-induced increment in conidiation, formation of pseudothecia, and melanin accumulation is possibly mediated by NO-cGMP signaling pathway, where NO works as a SGC activator triggering the signal transduction cascade.

\section{Materials And Methods}

\section{Strains and growth conditions}

Wild type and 5-AC-treated (the albinism mutant) S. eturmiunum strains were obtained from the Key Laboratory for Biology of Vegetable Diseases and Insect Pests of Shandong Province, Department of Plant Pathology, Shandong Agricultural University, Tai'an, China, and stored at $-80{ }^{\circ} \mathrm{C}$ in $15 \%$ glycerol and routinely maintained and grown in CM medium at $26^{\circ} \mathrm{C}$ (Zhao et al. 2019). Aspergillus nidulans L08030 was kindly donated by Dr. Caly Wang from the University of Southern California.

\section{Effects of exogenous NO on development of S. eturmiunum}

The effects of exogenous NO on the development of $S$. eturmiunum were we assayed by supplementing sodium nitroprusside dihydrate (SNP, Sigma, St. Louis, USA) into the culture $S$. eturmiunum at concentrations of $0,0.2,2,4,8 \mathrm{mmol} / \mathrm{L}$, respectively. For determining the possible pathways of NO signaling, the SNP-supplemented or SNP-non-supplemented cultures were also simultaneously supplemented either with NO scavenger CPTIO (Beyotime, Shanghai, China) at a concentration of $1 \mathrm{mmol} / \mathrm{L}$ or SGC specific inhibitor NS-2028 (Beyotime, Shanghai, China) at a concentration of $18 \mu \mathrm{mol} / \mathrm{L}$, and cultured at the same conditions. All cultures were incubated for $28 \mathrm{~d}$ in the continuous dark at $26^{\circ} \mathrm{C}$ to avoid the possible light effect of fungal development and SNP instability followed by observation for asexual and sexual development, as well as melanin accumulation. All the treatments were analyzed at least triplicate.

\section{Gene transcription analysis}

For RNA extraction, the mycelia were grounded with pestle and mortar in liquid nitrogen followed by extraction using Trizol (Takara, Ishiyama, Japan) as previously described (Lee et al. 1997). cDNA was 
generated using the Prime Script ${ }^{\text {TM }} \mathrm{RT}$ reagent kit (Takara, Ishiyama, Japan). Gene transcription analysis was conducted by quantitative real-time PCR (RT-PCR). The forward (F) and reverse (R) oligonucleotide primer sequences were listed in Table 1. RT-PCR was carried out using the Fast SYBR Green Master Mix (Thermo Fisher Scientific, USA). Gene expression levels were normalized using the endogenous control gene actin. To characterize the changes of mRNA levels of the genes influenced by NO, we employed $\mathrm{Ct}$ value of the initial amount of the candidate mRNA in a sample, as a quantitative measurement of gene expression strength under specific experimental conditions and simultaneously performed RT-PCR of the genes in the samples treated and untreated by SNP followed by double $\triangle \mathrm{Ct}$ analysis. The relative mRNA level was indicated by the exponentiation of $2^{-} \Delta \Delta \mathrm{Ct}$ (Livak and Schmittgen 2001). Every experiment was independently performed three times.

Table 1 Primers used for all experiments 


\begin{tabular}{|c|c|c|}
\hline Primers & Nucleotide sequences $(5-3)$ & Purpose \\
\hline actin- $\mathrm{F}$ & 5'-CATCCAGCTCAAGGACATCAT-3' & \multirow[t]{2}{*}{ qRT-PCR for actin } \\
\hline qactin-R & 5'-GTCGGATCAAGGTTCATCTTCT-3' & \\
\hline qmat1-F & 5'-ATACTGGCTACAGGGCAAATC-3' & \multirow[t]{2}{*}{ qRT-PCR for mat 1} \\
\hline $\mathrm{q} m a t 1-\mathrm{R}$ & 5'-GGACGAAGTTGGGAACAAGA-3' & \\
\hline qmat2-F & 5'-CGCATTTGGCACAACCTATC-3' & \multirow[t]{2}{*}{ qRT-PCR for mat2 } \\
\hline qmat2-R & 5'-GGCTATACTTGTAGTCGGGATG-3' & \\
\hline $\mathrm{q} b r \mid A-\mathrm{F}$ & 5'-GTCCAGACATTCACCCCCAG-3' & \multirow[t]{2}{*}{ qRT-PCR for $b r l A$} \\
\hline $\mathrm{q} b r / A-\mathrm{R}$ & 5'-CTTGTTGACATTGGGCTGGC-3' & \\
\hline qabaA-F & 5'-TCAAGATCCTGACGGAAGCG-3' & \multirow[t]{2}{*}{ qRT-PCR for $a b a A$} \\
\hline qabaA-R & 5'-AACGCAATGTTCAAGCGGTC-3' & \\
\hline $\mathrm{q} w e t A-\mathrm{F}$ & 5'-CACCTCGACCTCACACTTCC-3' & \multirow[t]{2}{*}{ qRT-PCR for wet $A$} \\
\hline qwetA-R & 5'-GGATGGCGATGAGACTGGAG-3' & \\
\hline qtyr-F & 5'-ATGGCATCGCTACTACATC-3' & \multirow[t]{2}{*}{ qRT-PCR for tyr } \\
\hline $\mathrm{q} t y r-\mathrm{R}$ & 5'-GATAGGGCAGGTGAGTTCT-3' & \\
\hline $\mathrm{q} p k s 1-\mathrm{F}$ & 5'-TGGGATCTTGTGGAAGCATAC -3' & \multirow[t]{2}{*}{ qRT-PCR for $p k s 1$} \\
\hline $\mathrm{q} p k s 1-\mathrm{R}$ & 5'-GTGCATAGACCGACAACTCTT-3' & \\
\hline $\mathrm{q} p k s 2-\mathrm{F}$ & 5'-CTTGCGGTTGGAGCATTTG -3' & \multirow[t]{2}{*}{ qRT-PCR for $p k s 2$} \\
\hline $\mathrm{qp} k s 2-\mathrm{R}$ & 5'-TTGTTCGTGGGTCGGTAATC-3' & \\
\hline $\mathrm{t} p k s 1-\mathrm{F}$ & 5'-tccttctcctgatcgctagcATGAACGTCCTCATTTTCGGAG-3' & \multirow{2}{*}{$\begin{array}{l}\text { For } p k s 1 \\
\text { transformation }\end{array}$} \\
\hline $\mathrm{t} p k s 1-\mathrm{R}$ & $\begin{array}{l}\text { 5'-acagaataactctcgctagcTTATAGCTTAAGACCTTGCTGGATC- } \\
3^{\prime}\end{array}$ & \\
\hline $\mathrm{t} p k s 2-\mathrm{F}$ & 5'-tccttctcctgatcgctagcCTCTACCGACССТСТСАCСC-3' & \multirow{2}{*}{$\begin{array}{l}\text { For } p k s 2 \\
\text { transformation }\end{array}$} \\
\hline $\mathrm{t} p k s 2-\mathrm{R}$ & 5'-acagaataactctcgctagcTCCAACGTCAGCAACCCATC-3' & \\
\hline $\begin{array}{l}\text { testpks1- } \\
\mathrm{F}\end{array}$ & 5'-GCGAGACCGCATTCCTAACT-3' & \multirow[t]{2}{*}{$\begin{array}{l}\text { Test } p k s 1 \\
\text { transformants }\end{array}$} \\
\hline $\begin{array}{l}\text { testpks1- } \\
\mathrm{R}\end{array}$ & 5'-TGTCAAGCTCCTCACGGAAC-3' & \\
\hline $\begin{array}{l}\text { testpks2- } \\
\mathrm{F}\end{array}$ & 5'-AGGATACTGTGGGGGTCTCC-3' & \multirow[t]{2}{*}{$\begin{array}{l}\text { Test pks2 } \\
\text { transformants }\end{array}$} \\
\hline testpks2- & 5'-TCAATCGGGTGGTCAAGAGC-3' & \\
\hline
\end{tabular}




\section{Assay of NO levels and NO producing capacity activity}

For assaying NO levels and NO producing capacity, the mycelia were withdrawn and rinsed twice with pure water and disrupted with mortar and pestle in liquid nitrogen. The well-powdered mycelia were then used for the assay of NO production and NO producing capacity. NO levels were determined by total NO assay kit (A012-1-2, Nanjing Jiancheng Bioengineering Institute, China), and its levels were indicated as micromolar per milligram protein ( $\mu \mathrm{mol} / \mathrm{mg}$ prot). NO producing capacity in homogenates was estimated using a total NOS assay kit (A014-2-1, Nanjing Jiancheng Bioengineering Institute, China). The protein content was determined by Coomassie Brilliant Blue using BSA (High-Tech Innovation, Inc., Shanghai, China) as standard. NO producing capacity was demonstrated as units $(U)$. One unit of NO producing capacity stands for the number of micromoles of NO produced by $1 \mathrm{mg}$ protein in $1 \mathrm{~min}$ (Zhao et al. 2015). Each experiment was independently performed at least three times.

\section{Pathways for melanin biosynthesis}

The pathway for melanin synthesis was determined by the application of specific pathway inhibitors. Dihydroxyphenylalanine (DOPA) pathway was assayed by supplementing the specific inhibitor arbutin (Alfa Aesar, USA) at a final concentration of $30 \mathrm{mg} / \mathrm{L}$ (Gong et al. 2013), and the dihydroxynaphthalene (DHN) pathway was assessed by the addition of the pathway specific inhibitor tricyclazole (Adamas, China) at a final concentration of $30 \mathrm{mg} / \mathrm{L}$ (Pal et al. 2014) into the cultures, respectively. The CM media were inoculated by placing a mycelium plug cut from the margins of an actively growing colony, and incubated at $26^{\circ} \mathrm{C}$ for $7 \mathrm{~d}$ followed by observation of growth and pigmentation. Every experiment was independently performed three times.

\section{Tyrosinase activity}

Tyrosinase activity was assayed as described (Lejczak et al. 1987; Likhitwitayawuid and Sritularak, 2001) with slight modification. Briefly, 20 mmol/L phosphate buffer (pH 6.8), 2 mmol/L L-DOPA (Sigma, St. Louis, USA), and protein extracts were mixed and reacted at $30^{\circ} \mathrm{C}$ for $30 \mathrm{~min}$. Then the formation of dopachrome was measured at $475 \mathrm{~nm}$. Tyrosinase activity was demonstrated as units (U). One unit of tyrosinase activity stands for the number of micromoles of dopachrome produced by $1 \mathrm{mg}$ protein in $1 \mathrm{~min}$. The test was performed in triplicate.

\section{Melanin extraction}

Melanin extraction from the fungal biomass was performed as described previously (Pal et al. 2014) with a slight modification. In brief, the mycelia were crushed with $2 \mathrm{~mol} / \mathrm{L} \mathrm{NaOH} \mathrm{(pH} \mathrm{10.5)} \mathrm{and} \mathrm{placed} \mathrm{for} 48 \mathrm{~h}$. Next, the mixture was centrifuged at $3500 \mathrm{~g}$ for $15 \mathrm{~min}$ and the resultant supernatant was mixed with $6 \mathrm{~mL}$ of a mixture solvent consisting of chloroform, ethyl acetate and ethanol ( $2 \mathrm{~mL}$ each), and vortexed 
for $5 \mathrm{~min}$ at room temperature to remove lipids. After removal of the organic layer, the aqueous layer was acidified by $2 \mathrm{~mol} / \mathrm{L} \mathrm{HCl}$ to $\mathrm{pH} 2.5$ followed by incubation overnight at room temperature and then centrifuged at $3500 \mathrm{~g}$ for $15 \mathrm{~min}$ to remove carbohydrates and proteins. The resultant precipitate was dried at room temperature, and dissolved in $2 \mathrm{~mol} / \mathrm{L} \mathrm{NaOH}$ followed by centrifugation at $3500 \mathrm{~g}$ for $15 \mathrm{~min}$. The supernatant was then acidified with $6 \mathrm{~mol} / \mathrm{L} \mathrm{HCl}$. And centrifuged at $3500 \mathrm{~g}$ for $15 \mathrm{~min}$. The resultant precipitate was washed with distilled water and dried at room temperature, and used until further analysis.

\section{Heterologous expression of the genes involved in biosynthesis of DHN melanin}

A. nidulans L08030 (Chiang et al. 2013) was used as heterologous host to express the genes involved in DHN melanin biosynthesis. For constructing the heterologous transformants, one $1.5 \mathrm{~Kb}$ up- and downstream of the two pks genes were fused with pyrG by fusion PCR using the primers listed in Table 1. The fused DNA fragments were then transformed to $w A$ locus in A. nidulans L08030 following the protocol described previously (Brock et al. 2008). All constructions were confirmed by diagnostic PCR.

\section{Protection of conidial germination under UV irradiation}

The conidia were irradiated by UV ( $30 \mathrm{~W}$ ) at a distance of $65 \mathrm{~cm}$ for $15 \mathrm{~min}$. After exposure to UV, the conidia were suspended in $20 \%$ Tween 80 and reconstituted to a final concentration of $500 \mathrm{cfu} / \mathrm{mL}$ using a hemocytometer. A total of $200 \mu \mathrm{L}$ was pipetted to plate spreading on GMM agar media. For germination assay, the conidia-spread plates were incubated at $37^{\circ} \mathrm{C}$ for $24 \mathrm{~h}$. The germination rate was calculated by the number of germinated conidia divided by the number of conidia in $200 \mu \mathrm{L}$ conidia suspension.

\section{Statistical analysis}

All determinations were carried out in triplicate and the results are expressed as mean \pm standard deviation (SD). Excel was used to compare the difference between means by $t$-tests. Values of $p<0.05$ were considered significant.

\section{Results}

Phenotype changes of S. eturmiunum induced by different levels of NO

The morphogenesis in filamentous fungi often correlates with cellular levels of NO (Chiuchetta and Castro-Prado 2005; Vieira et al. 2009). To probe how NO regulates the development of filamentous fungi, we conducted the culture of onion pathogenic $S$. eturmiunum by supplementing SNP. Under laboratory growth conditions, the fungal colony was densely dotted with brown-colored conidia, and was more densely dotted upon exposure to $0.2 \mathrm{mmol} / \mathrm{L}$ SNP. However, the brown-colored conidia were reduced and gradually disappeared upon exposure to SNP at 2, 4, and $8 \mathrm{mmol} / \mathrm{L}$, respectively (Fig. 1A).

Next, we chose $0.2 \mathrm{mmol} / \mathrm{L}$ and $2 \mathrm{mmol} / \mathrm{L}$ SNP as the external NO source to observe NO-induced changes of phenotype. To confirm the regulatory roles of NO in the changes of phenotype, we also supplemented NO specific scavenger CPTIO $(1 \mathrm{mmol} / \mathrm{L})$. The addition of CPTIO resulted in the retarded 
mycelial growth and the presence of more albinism mycelia on the surface of colonies especially in control and the cultures supplemented with $0.2 \mathrm{mmol} / \mathrm{L} \mathrm{SNP}$ (Fig. 1B). To test the possible mechanisms of NO-induced phenotype changes of S. eturmiunum, we further used SGC specific inhibitor NS-2080 (18 $\mu \mathrm{mol} / \mathrm{L}$ ) to block the formation of CGMP. Intriguingly, addition of NS-2080 resulted in the presence of more albinism mycelia and retarded mycelial growth in control cultures and the cultures containing $0.2 \mathrm{mmol} / \mathrm{L} \mathrm{SNP}$ (Fig. 1B).

\section{Involvements of NO in the formation of conidia and pseudothecia}

As a signaling molecule, NO is involved in conidiation (Wang and Higgins 2005; Gong et al. 2007), and the formation of sexual cleistothecia in Aspergillus species (Baidya et al. 2011). To test whether NO affects the formation of the propagules in $S$. eturmiunum, we also assayed its conidiation and the formation of pseudothecia in the cultures supplemented SNP, cPTIO, and NS-2080, respectively. In the control cultures without SNP supplement, conidiation was observed on day 28 post inoculation. Morphologically, the produced conidia intertwine tightly with mycelia, and can hardly be isolated from cultures for counting. To this end, we portrayed conidiation qualitatively by visually comparing the density of the conidia present in the same square of culture plates in different treatments. In the control cultures, the promoted conidiation was observed upon exposure to $0.2 \mathrm{mmol} / \mathrm{L} \mathrm{SNP}$, and was largely reduced upon exposure to $2 \mathrm{mmol} / \mathrm{L}$. The presence of CPTIO compromised conidiation in the SNPsupplemented cultures and totally abolished in control cultures. Intriguingly, application of NS-2080 resulted in the impairment of conidiation even in the presence of SNP (Fig. 2A). SNP supplement also increased the formation of pseudothecia especially in the cultures exposed to $2 \mathrm{mmol} / \mathrm{L}$ SNP. Similarly, application of CPTIO and NS-2080 inhibited the formation of pseudothecia (Fig. 2B). To further identify the effects of NO on the formation of pseudothecia, we also prepared the cultures exposed to $4 \mathrm{mmol} / \mathrm{L}$ and $8 \mathrm{mmol} / \mathrm{L}$ SNP to observe the correlation of NO levels with the number of pseudothecia. As shown in Fig. 3A, the maximum number of pseudothecia was observed upon exposure to $2 \mathrm{mmol} / \mathrm{L}$ SNP and largely reduced in the cultures exposed to 4 and $8 \mathrm{mmol} / \mathrm{L}$ (Fig. 3A). Similar to conidiation, application of CPTIO and NS-2080 all reduced the number of pseudothecia especially in control and the cultures exposed to $0.2 \mathrm{mmol} / \mathrm{L}$ SNP (Fig. 3B).

\section{External NO application changes the expression of genes involved in conidiation and the formation of pseudothecia}

In Aspergillus molds, asexual development is orchestrated by BrlA, AbaA, and WetA transcriptional cascade (Lind et al. 2018). To testify the relevance between conidiation and expression of the three transcription factors in S. eturmiunum upon external NO application, we conducted the RT-PCR assay of the genes encoding BrlA (GenBank accession number: MT925646), AbaA (GenBank accession number: MT925645), and WetA (GenBank accession number: MT925644). SNP application at $0.2 \mathrm{mmol} / \mathrm{L}$ triggered the maximum increase in transcription levels of $b r l A$, abaA, and wetA. Interestingly, application of CPTIO and NS-2080 all reduced expression levels down to 0.62 folds for brlA (Fig. 4A), 0.64 folds for 
abaA (Fig. 4B), and 0.59 folds for wetA (Fig. 4C), respectively. Similar to conidiation, exposure to $2 \mathrm{mmol} / \mathrm{L}$ SNP also caused the maximum increase in transcription levels of mat1 (up to 4.8 folds) and mat2 (up to 3.8 folds), the two genes involved in sexual reproduction, and reduced the expression levels of mat1 and mat2 upon application of cPTIO and NS-2080, respectively (Fig. 4D, F).

\section{NO-stimulated biosynthesis of melanins correlates with increased conidiation and formation of pseudothecia}

Biosynthesis of melanins in fungi plays a crucial role in defending fungal cells against environmental stresses. Accumulation of melanin in fungal propagules contributes to virulence and capacity to survive in harsh surroundings (Valiante et al. 2016). Interestingly, exposure to $2 \mathrm{mmol} / \mathrm{L}$ SNP stimulated production of melanins. Application of CPTIO and NS2080 compromised melanin biosynthesis especially in control and the cultures exposed to $0.2 \mathrm{mmol} / \mathrm{L} \mathrm{SNP} \mathrm{(Fig.} \mathrm{5).} \mathrm{To} \mathrm{determine} \mathrm{the} \mathrm{possible} \mathrm{types} \mathrm{of}$ melanins produced in $S$. eturmiunum, we further supplemented arbutin and tricyclazole, the two specific inhibitors for DOPA and DHN biosynthetic pathways, respectively. Upon addition of arbutin or tricyclazole, the dark-brown colonies were bleached to albinism mycelia (Fig. 6A). In addition, supplement of the two inhibitors for melanin biosynthesis also impaired conidiation (Fig. 6B) and the formation of pseudothecia (Fig. 6C, D).

NO production correlates with the biosynthesis of melanin in S. eturmiunum

NO is involved in many physiological processes of filamentous fungi and the production of NO has been demonstrated in many fungal species although the search for the genes coding for NOS-like proteins (NOSL) in fungal genomes remains unfruitful (Li et al. 2010). To test the capacity to produce NO by $S$. eturmiunum, we used the term "NO-producing capacity" to stand for NOS-like activity. In addition, we also assayed NO levels under the supplement of SNP, arbutin, and tricyclazole, respectively. Similar to other NO-producing filamentous fungi, NO-producing capacity was also observed in S. eturmiunum, and was reduced following supplement of SNP. Reduction in NO-producing capacity was also seen in the cultures supplemented with arbutin or tricyclazole. Intriguingly, simultaneous supplement of SNP and arbutin, or SNP and tricyclazole further reduced NO producing capacity (Fig. 7A). Accordingly, NO levels were also reduced evidently in the cultures supplemented with arbutin or tricyclazole (Fig. 7B). Notably, following the reduction in NO levels, melanin accumulation was decreased remarkably even in the presence of SNP (Fig. 7C). In order to further correlate NO production and melanin biosynthesis, we analyzed NO-producing capacity in 5-AC-treated S. eturmiunum. Obviously, 5-AC treatment resulted in the impairment in NO production, the activity of tyrosinase, as well as melanin biosynthesis, which coincides with the cultures supplemented with arbutin and tricyclazole (Fig. 8A, B). Genome analysis resulted in the annotation of two polyketide synthase genes possibly involved in DHN-melanin synthesis (PKS1 and PKS2, GenBank accession numbers: MT925643 and MT925643) (Pal et al. 2014; Akamatsu et al. 2010), and one tyrosinase gene tyr (GenBank accession numbers: MT925641) for DOPA-melanin biosynthesis (Choi et al. 2012; Kumar et al. 2015). Intriguingly, SNP treatment resulted in 9.4 folds increased transcription for $p k s 1,5.4$ folds increased transcription for $p k s 2$, and 7.4 folds increased transcription for tyr. In contrast, 
5-AC treatment down regulated I to 0.19 folds in transcription for $p k s 1,0.065$ folds for $p k s 2$, and 0.094 folds for $\operatorname{tyr}$ (Fig. $8 \mathrm{C}$ ). To further identify the function of $p k s 1$ and $p k s 2$, we also constructed the heterologous transformants of pks1 and pks2 using wA locus in Aspergillus nidulans L08030. Heterologous expression of $p k s 1$ and $p k s 2$ in $w A$ locus resulted in the presence of brown pigment in the conidia of either $p k s 1$ mutant or $p k s 2$ mutant (Fig. 9A). Moreover, the two transformants showed similar germination rate with conidia of $A$. nidulans after UV irradiation (Fig. 9B). Collectively, melanin biosynthesis is also dependent on cellular levels of NO in S. eturmiunum.

\section{Discussion}

The formation of conidia and pseudothecia of the onion pathogenic $S$. eturmiunum is the critical stage for its transmission. However, how the development of the two propagules is regulated remains to be fully understood. In the study, we showed that NO is necessary for conidiation and the formation of pseudothecia in S. eturmiunum. Application of NO scavenger CPTIO abolishes the formation of conidia and pseudothecia, as well as melanin production. In control cultures supplement of SNP results in an increased formation of conidia at $0.2 \mathrm{mmol} / \mathrm{L}$, and pseudothecia at $2 \mathrm{mmol} / \mathrm{L}$. SNP supplement also triggered increased biosynthesis of melanin, which can be inhibited upon addition of either arbutin or tricyclazole, the specific inhibitors for DOPA and DHN melanin synthetic pathway, respectively. Moreover, the enhanced biosynthesis of melanin coincides with the increased formation of the two propagules that are impaired following the inhibition of melanin biosynthesis (Fig. 10).

The small free radical NO is a short-lived but highly reactive diatomic gas (Brüne 2010). Because it is highly diffusible within the cell and through cell membranes (Lancaster 1997), NO functions as a transient, local, intracellular or intercellular signaling molecule in diverse biological systems (Culotta \& Koshland 1992). One of the important mechanisms that NO regulates physiological processes of living system is the binding of NO with transition metals of metalloproteins such as SGC, a hemoprotein that has evolved to bind selectively with NO (Boon \& Marletta 2005). The activation of sGC by NO results in the production of the secondary messenger cyclic GMP (cGMP) (Friebe \& Koesling 2003) that binds to protein kinase $\mathrm{G}(\mathrm{PKG})$, and forms the central downstream mediator of NO-cGMP signaling pathway, and mediates pathway-specific cellular responses via the phosphorylation of phosphorylation-dependent transcriptional factors, such as the cAMP-response-element-binding protein (Contestabile 2008), and activates its downstream targets (Tomankova et al. 2017).

In filamentous fungi, endogenous production of NO correlates with mycelial growth and conidia formation (Marcos et al. 2020). In A. nidulans, increased production of NO was detected in the transition from vegetative growth to conidiation (Marcos et al. 2016). Similar to A. nidulans, our results showed that the presence of NO-producing capacity followed by intracellular production of NO correlates with the regular conidiation, which is compromised following the addition of NO scavenger $\mathrm{CPTIO}$. This indicates that maintaining a certain level of cellular NO underpins the vegetative growth and asexual development in S. eturmiunum. Interestingly, addition of NO-releasing compound SNP resulted in an evident reduction in NO-producing capacity (Fig. 7A), which suggests that NO-producing capacity can be self-regulated in 
response to alteration of the cellular NO levels. In addition, SNP supplement at concentrations lower than $0.2 \mathrm{mmol} / \mathrm{L}$ also promotes conidiation, which implicates that external application of $\mathrm{NO}$ at lower concentrations favors the transcription of $b r l A, a b a A$, and wetA, the three transcriptional factors involved in conidiation (Chen et al. 2020).

Cellular NO levels also affect sexual development in filamentous fungi (reviewed by Zhao et al. 2020). In Aspergillus nidulans, the increase in cellular NO levels by disrupting the genes encoding flavohemoglobin or supplementing NO-releasing compound promotes the formation of cleistothecia (Baidya et a., 2011). Similar to A. nidulans, supplement of SNP at $2 \mathrm{mmol} / \mathrm{L}$ increased transcription of mat1 and mat2 followed by increased formation of pseudothecia, which indicates that the higher NO levels also tend to induce sexual development in S. eturmiunum.

Melanins production in fungi is believed to protect hyphae and propagules from environmental stresses (Bell and Wheeler 1986; Butler and Day 1998), and to serve as a virulence factor (Langelder et al. 2003; Nsanchuk and Casadevll, 2003). Disruption of melanin biosynthesis compromised fungal ability for survival and longevity (Engh et al. 2007). In Pestalotiopsis microspore, the production of polyketidederived $\mathrm{DNH}$ melanin is required for the formation of integrated conidia and viability in addition to morphogenesis, germination and viability (Yu et al. 2015). Moreover, production of DNH melanin is also linked to the development of sexual fruiting body, and is controlled by specific regulatory genes involved in sexual differentiation in Sordaria macrospora (Engh et al. 2007). In our study, external addition of NO also promotes the transcription of the two genes encoding two polyketide synthases, and the gene coding for tyrosinase followed by increased melanin accumulation and formation of conidia and pseudothecia. Notably, inhibiting biosynthesis of DOPA and DNH melanin all lead to the impairment in the formation of conidia and pseudothecia. This indicates that biosynthesis of both DOPA and DNH melanin is required for asexual and sexual development in S. eturmiunum.

The melanins present in fungal cells are involved in their protection from UV radiation desiccation, salinity and oxidation (Pacelli et al. 2020). Melanins in phytopathogenic or human pathogenic fungi are also involved in the protection against ROS attack from host defense (Papon et al. 2020). In filamentous fungi, most ascomycetes produce DHN-melanin (Gonçalves et al. 2012). While in the ubiquitous humanpathogenic fungus Aspergillus fumigatus, the pathogen that causes fatal lung infection in immunocompromised individuals, produces both DOPA and DHN melanins (Langfelder et al. 2003). The presence of DHN melanin in conidia protects from phagocytic uptake and ROS-induced intracellular killing by frugivorous amoeba Protostelium aurantium and disrupts its autonomous defense (Ferling et al. 2020). In Sporothrix schenckii, production of DOPA melanin in the presence of tyrosine in fungal cell confers more resistance to nitrogen-derived oxidants and UV irradiation (Almeida-Paes et al. 2012). In our study, heterologous expression of $p k s 1$ and $p k s 2$ all resulted in the production of pigmented conidia with resistance to UV irradiation. In this context, the production of DOPA and DHN melanins found in phytopathogenic $S$. eturmiunum and their tight connections with the formation of conidia and pseudothecia implicate that this fungus possesses more resistance to the attacks from environmental stressors than those producing DNH melanins alone. 
The primary sensor of NO soluble guanylate cyclase (sGC) orchestrates NO-cGMP-PKG signaling pathway, and has been implicated in many essential physiological processes and disease conditions in mammals (Kang et al. 2019). Several studies have reported that sporulation in filamentous fungi is promoted by application of external NO but inhibited by SGC inhibitor L-NAME or ODQ. However, sporulation can be restored by exogenous cGMP (Zhao et al. 2020). In our study, NO promoted formation of conidia and pseudothecia, and melanin production can also be compromised by SGC specific inhibitor NS-2080 even in the presence of SNP. This implicates the existence of NO-cGMP-PKG signaling pathway in $S$. eturmiunum that mediates the increased transcription of the genes encoding the downstream regulators for conidiation, formation of pseudothecia and melanin biosynthesis.

It should be noted that, in our study, in contrast to the increased formation of conidia and pseudothecia by lower concentrations of SNP ( $\leq 2 \mathrm{mmol} / \mathrm{L}$ ), external supplement of SNP at higher concentrations ( $\geq$ $4 \mathrm{mmol} / \mathrm{L}$ ) inhibited or compromised the formation of the two propagules and melanin biosynthesis. This indicates that higher concentrations of NO can covalently binds with thiols in active cysteine residues (Amal et al. 2019; Heinrich et al. 2013), leading to S-nitrosylation of active proteins and subsequent negative feedback of NO signaling (Zhao et al. 2016).

This study revealed the NO-mediated mechanisms in regulating asexual and sexual development of onion blight pathogen $S$. eturmiunum. Further studies should be directed to the identification of downstream transcription factors of NO-cGMP-PKG, which is undertaking in our lab. However, our data reveal, for the first time, that the cellular levels of NO determines the fate of asexual and sexual development of $S$. eturmiunum. Moreover, the specific requirement for NO by $S$. eturmiunum in the development of conidia and pseudothecia implicates a possible strategy to curb the transmission of this onion pathogen by applying higher concentration of NO-releasing compound to impede its asexual and sexual development.

\section{Conclusion}

Our results confirmed that $\mathrm{NO}$ is necessary for conidiation and the formation of pseudothecia in $S$. eturmiunum. Conidiation is promoted upon exposure to $0.2 \mathrm{mmol} / \mathrm{L} \mathrm{SNP}$, while pseudothecia formation is enhanced upon exposure to $2 \mathrm{mmol} / \mathrm{L}$ SNP. Application of NO scavenger CPTIO and SGC specific inhibitor NS2080 abolishes their formation of conidia and pseudothecia, as well as melanin production. In addition, melanin accumulation in the fungus is achieved either by DOPA and DHN melanin synthetic pathway, which correlates with its asexual and sexual development, and confers the capacity for $S$. eturmiunum to transmit and infect effectively even in harsh environment.

\section{Abbreviations}

5-AC: 5-azacytidine; cAMP: cyclic AMP; cGMP: cyclic GMP; cPTIO: carboxy-CPTIO; DHN: dihydroxynaphthalene; DOPA: L-dihydroxyphenylalanine; MAPK: mitogen-activated protein kinase; NO: 
nitric oxide; PKC: protein kinase C; PKS: polyketide synthase; sGC: soluble guanylate cyclase; TYR: tyrosinase

\section{Declarations}

\section{Acknowledgements}

Not applicable.

\section{Adherence to national and international regulations}

Not applicable.

\section{Authors' contributions}

$Y Z, X Z$ and $W Z$ designed the experiments, analyzed the data, and WZ and $Y Z$ wrote the manuscript. $Y Z$, WY and MS performed the experiments. The authors read and approved the final manuscript.

\section{Funding}

This work is financially supported by a grant from the National Natural Science Foundation of China (31230001) for Dr Xiuguo Zhang.

\section{Availability of data and materials}

All data generated or analyzed during this study are included in this published article.

\section{Ethics approval and consent to participate}

Not applicable.

\section{Consent for publication}

All authors have read the paper and consent for publication

\section{Competing interests}

The authors declare that they have no competing interests.

\section{Author details}

${ }^{1}$ Key Laboratory for Biotechnology on Medicinal Plants of Jiangsu Province, Jiangsu Normal University, Xuzhou 221116, Jiangsu, China. ${ }^{2}$ Key Laboratory for Biology of Vegetable Diseases and Insect Pests of Shandong Province, Department of Plant Pathology, Shandong Agricultural University, Tai'an 271018, Shandong, China 


\section{References}

1. Adams TH, Wieser JK, Yu JH (1998) Asexual sporulation in Aspergillus nidulans. Microbiol Mol Biol Rev 62(1):35-54

2. Affeldt KJ, Brodhagen M, Keller NP (2012) Aspergillus oxylipin signaling and quorum sensing pathways depend on g protein-coupled receptors. Toxins (Basel) 4(9):695-717. https://doi:10.3390/toxins4090695

3. Akamatsu HO, Chilvers MI, Stewart JE, Peever TL (2010) Identification and function of a polyketide synthase gene responsible for 1,8-dihydroxynaphthalene-melanin pigment biosynthesis in Ascochyta rabiei. Curr Genet 56(4):349-360. https://doi:10.1007/s00294-010-0306-2

4. Al-Laaeiby A, Kershaw MJ, Penn TJ, Thornton CR (2016) Targeted disruption of melanin biosynthesis genes in the human pathogenic fungus Lomentospora prolificans and its consequences for pathogen survival. Int J Mol Sci 17(4):444. https://doi:10.3390/ijms17040444

5. Almeida-Paes R, Frases S, Araújo Gde S, de Oliveira MME, Gerfen GJ, Nosanchuk JD, ZancopéOliveira RM (2012) Biosynthesis and functions of a melanoid pigment produced by species of the sporothrix complex in the presence of L-tyrosine. Appl Environ Microbiol 78(24):8623-8630. https://doi:10.1128/AEM.02414-12

6. Alviano CS, Farbiarz SR, De Souza W, Angluster J, Travassos LR (1991) Characterization of Fonsecaea pedrosoi melanin. Journal of General Microbiology 137(4):837-844. https://doi:10.1099/00221287-137-4-837

7. Amal H, Gong G, Gjoneska E, Lewis SM, Wishnok JS, Tsai LH, Tannenbaum SR (2019) S-nitrosylation of E3 ubiquitin-protein ligase RNF213 alters non-canonical Wnt/Ca ${ }^{+2}$ signaling in the P301S mouse model of tauopathy. Translational Psychiatry 9(1):44. https://doi:10.1038/s41398-019-0388-7

8. Amin S, Thywissen A, Heinekamp T, Saluz HP, Brakhage AA (2014) Melanin dependent survival of Apergillus fumigatus conidia in lung epithelial cells. Int J Med Microbiol 304(5-6):626-636. https://doi:10.1016/j.jimm.2014.04.009

9. Andersen B, Frisvad JC (2004) Natural occurrence of fungi and fungal metabolites in moldy tomatoes. J Agric Food Chem 52(25):7507-7513. https://doi:10.1021/jf048727k

10. Aukema HM, Winter T, Ravandi A, Dalvi S, Miller DW, Hatch GM (2016) Generation of bioactive oxylipins from exogenously added arachidonic, eicosapentaenoic and docosahexaenoic acid in primary human brain microvessel endothelial cells. Lipids 51(5):591-599.

https://doi:10.1007/s11745-015-4074-0

11. Baidya S, Cary JW, Grayburn WS, Calvo AM (2011) Role of nitric oxide and flavohemoglobin homolog genes in Aspergillus nidulans sexual development and mycotoxin production. Appl Environ Microbiol 77(15):5524-5528. https://doi 10.1128/AEM.00638-11

12. Bell AA, Wheeler MH (1986) Biosynthesis and functions of fungal melanins. Annual Review of Phytopathology 24(1):411-451. https://doi:abs/10.1146/annurev.py.24.090186.002211 
13. Boon EM, Marletta MA (2005) Ligand specificity of H-NOX domains: from sGC to bacterial NO sensors. J Inorg Biochem 99(4):892-902. https://doi:10.1016/j.jinorgbio.2004.12.016

14. Boylan MT, Mirabito PM, Willett CE, Zimmerman CR, Timberlake WE (1987) Isolation and physical characterization of three essential conidiation genes from Aspergillus nidulans. Mol Cell Biol 7:3113-3118. https://doi 10.1128/mcb.7.9.3113

15. Brock $M$, Jouvion $G$, Droin-Bergère $S$, Dussurget $O$, Nicola MA, Ibrahim-Granet $O$ (2008) Bioluminescent Aspergillus fumigatus, a new tool for drug efficiency testing and in vivo monitoring of invasive aspergillosis. Appl Environ Microbiol 74(22):7023-7035. https://doi:10.1128/AEM.01288-08

16. Brüne B (2010) Nitric oxide: a short-lived molecule stays alive. Pharmacol Res 61(4):265-268. https://doi:10.1016/j.phrs.2009.11.002

17. Butler MJ, Gardiner RB, Day AW (2009) Melanin synthesis by Sclerotinia sclerotiorum. Mycologia 101(3):296-304. https://doi:10.3852/08-120

18. Chamilos G, Carvalho A (2020) Aspergillus fumigatus DHN-Melanin. Current Topics Microbiology Immunology 425:17-28. https://doi:10.1007/82_2020_205

19. Chang PK, Scharfenstein LL, Mack B, Wei Q, Gilbert M, Lebar M, Cary JW (2019) Identification of a copper-transporting ATPase involved in biosynthesis of $A$. flavus conidial pigment. Appl Microbiol Biotechnol 103(12):4889-4897. https://doi:10.1007/s00253-019-09820-0

20. Chen JF, Liu Y, Tang GR, Jin D, Chen X, Pei Y, Fan Y (2020) The secondary metabolite regulator, BbSmr1, is a central regulator of conidiation via the BrlA-AbaA-WetA pathway in Beauveria bassiana. Environ Microbiol. 10.1111/1462-2920.15155. https://doi:10.1111/1462-2920.15155

21. Chiang YM, Oakley CE, Ahuja M, Entwistle R, Schultz A, Chang SL, Sung CT, Wang CC, Oakley BR (2013) An efficient system for heterologous expression of secondary metabolite genes in Aspergillus nidulans. J Am Chem Soc 135(20):7720-7731. https://doi:10.1021/ja401945a

22. Chiuchetta SJR, Castro-Prado MAA (2005) Genotoxic evaluation of sodium nitroprusside in Aspergillus nidulans. Genetics Molecular Biology 28:798-803. https://doi:10.1590/S141547572005000500023

23. Choi YJ, Uehara Y, Park JY, Chung KW, Ha YM, Kim JM, Song YM, Chun P, Park JW, Moon HR, Chung HY (2012) Suppression of melanogenesis by a newly synthesized compound, MHY966 via the nitric oxide/protein kinase G signaling pathway in murine skin. J Dermatol Sci 68(3):164-171. https://doi:10.1016/j.jdermsci.2012.09.014

24. Contestabile A (2008) Regulation of transcription factors by nitric oxide in neurons and in neuralderived tumor cells. Prog Neurobiol 84(4):317-328. https://doi:10.1016/j.pneurobio.2008.01.002

25. Culotta E, Koshland DE Jr (1992) NO news is good news. Science 258(5090):1862-1865. https://doi:10.1126/science.1361684

26. Cunha MM, Franzen AJ, Seabra SH, Herbst MH, Vugman NV, Borba LP, de Souza W, Rozental S (2010) Melanin in Fonsecaea pedrosoi: a trap for oxidative radicals. BMC Microbiol 10:80. https://doi:10.1186/1471-2180-10-80 
27. Engh I, Nowrousian M, Kück U (2007) Regulation of melanin biosynthesis via the dihydroxynaphthalene pathway is dependent on sexual development in the ascomycete Sordaria macrospora. FEMS Microbiol Lett 275(1):62-70. https://doi:10.1111/j.1574-6968.2007.00867.x

28. Ferling I, Dunn JD, Ferling A, Soldati T, Hillmann F (2020) Conidial melanin of the human-pathogenic fungus Aspergillus fumigatus disrupts cell autonomous defenses in amoebae. mBio 11(3):e00862e00820. https://doi:10.1128/mBio.00862-20

29. Fernandez J, and Rivera-vargas L (2008) Leaf blight of onion caused by Pleosporaeturmiuna, teleomorph of Stemphylium eturmiunum. Journal of Agriculture-University of Puerto Rico 92:235239

30. Fischer GJ, Keller NP (2016) Production of cross-kingdom oxylipins by pathogenic fungi: An update on their role in development and pathogenicity. J Microbiol 54(3):254-264. https://doi:10.1007/s12275-016-5620-z

31. Friebe A, Koesling D (2003) Regulation of nitric oxide-sensitive guanylyl cyclase. Circ Res 93(2):96105. https://doi:10.1161/01.RES.0000082524.34487.31

32. Gonçalves RC, Lisboa HC, Pombeiro-Sponchiado SR (2012) Characterization of melanin pigment produced by Aspergillus nidulans. World Journal of Microbiology \& Biotechnology 28(4):1467-1474. https://doi:10.1007/s11274-011-0948-3

33. Gong S, Yin M, Yun Z (2013) Kinetics of inhibitory effect of isoferulic acid on mushroom tyrosinase. J Cosmet Sci 64(4):235-241

34. Gong X, Fu Y, Jiang D, Li G, Yi X, Peng Y (2007) L-arginine is essential for conidiation in the filamentous fungus Coniothyrium minitans. Fungal Genetis Biology 44:1368-1379. https://doi:10.1016/j.fgb.2007.07.007

35. Hassan L, Lin L, Sorek H, Sperl LE, Goudoulas T, Hagn F, Germann N, Tian C, Benz JP (2019) Crosstalk of cellulose and mannan perception pathways leads to inhibition of cellulase production in several filamentous fungi. mBio 10(4):e00277-e00219. https://doi:10.1128/mBio.00277-19

36. Heinrich TA, da Silva RS, Miranda KM, Switzer CH, Wink DA, Fukuto JM (2013) Biological nitric oxide signalling: chemistry and terminology. Br J Pharmacol 169(7):1417-1429. https://doi:10.1111/bph.12217

37. Kang Y, Liu R, Wu JX, Chen L (2019) Structural insights into the mechanism of human soluble guanylate cyclase. Nature 574(7777):206-210. https://doi:10.1038/s41586-019-1584-6

38. Kozubowski L, Lee SC, Heitman J (2009) Signalling pathways in the pathogenesis of Cryptococcus. Cell Microbiol 11(3):370-380. https://doi:10.1111/j.1462-5822.2008.01273.x

39. Krijgsheld P, Bleichrodt R, van Veluw GJ, Wang F, Müller WH, Dijksterhuis J, Wösten HA (2013) Development in Aspergillus. Stud Mycol 74(1):1-29. https://doi 10.3114/sim0006

40. Kumar M, Chand R, Dubey RS, Shah K (2015) Effect of tricyclazole on morphology, virulence and enzymatic alterations in pathogenic fungi Bipolaris sorokiniana for management of spot blotch disease in barley. World J Microbiol Biotechnol 31(1):23-35. https://doi: 10.1007/s11274-014-17563

Page $17 / 31$ 
41. Lambou K, Malagnac F, Barbisan C, Tharreau D, Lebrun MH, Silar P (2008) The crucial role of the Pls1 tetraspanin during ascospore germination in Podospora anserina provides an example of the convergent evolution of morphogenetic processes in fungal plant pathogens and saprobes. Eukaryot Cell 7(10):1809-1818. https://doi 10.1128/EC.00149-08

42. Lancaster JR Jr (1997) A tutorial on the diffusibility and reactivity of free nitric oxide. Nitric Oxide 1(1):18-30. https://doi:10.1006/niox.1996.0112

43. Langfelder K, Streibel M, Jahn B, Haase G, Brakhage AA (2003) Biosynthesis of fungal melanins and their importance for human pathogenic fungi. Fungal Genet Biol 38(2):143-158. https://doi:10.1016/s1087-1845(02)00526-1

44. Lee D, Meyer K, Chapple C, Douglas CJ (1997) Antisense suppression of 4-coumarate:coenzyme A ligase activity in Arabidopsis leads to altered lignin subunit composition. Plant Cell 9(11):19851998. https://doi:10.1105/tpc.9.11.1985

45. Lee SC, Ni M, Li W, Shertz C, Heitman J (2010) The evolution of sex: a perspective from the fungal kingdom. Microbiol Mol Biol Rev 74(2):298-340. https://doi:10.1128/MMBR.00005-10

46. Lejczak B, Kafarski P, Makowiecka E (1987) Phosphonic analogues of tyrosine and 3,4dihydroxyphenylalanine (dopa) influence mushroom tyrosinase activity. Biochem J 242(1):81-88. https://doi:10.1042/bj2420081

47. Li B, Fu Y, Jiang D, Xie J, Cheng J, Li G, Hamid MI, Yi X (2010) Cyclic GMP as a second messenger in. the nitric oxide-mediated conidiation of the mycoparasite Coniothyrium minitans. Appl Environ Microbiol 76(9):2830-2836. https://doi:10.1128/AEM.02214-09

48. Likhitwitayawuid K, Sritularak B (2001) A new dimeric stilbene with tyrosinase inhibitiory activity from Artocarpus gomezianus. J Nat Prod 64(11):1457-1459. https://doi:10.1021/np0101806

49. Lind AL, Lim FY, Soukup AA, Keller NP, Rokas A (2018) A LaeA- and BrlA-dependent cellular network governs tissue-specific secondary metabolism in the human pathogen Aspergillus fumigatus. mSphere 3(2):e00050-e00018. https://doi:10.1128/mSphere.00050-18

50. Livak KJ, Schmittgen TD (2001) Analysis of relative gene expression data using real-time quantitative PCR and the 2(-Delta Delta C(T)) method. Methods 25(4):402-408. https://doi:10.1006/meth.2001.1262

51. Maier J, Hecker R, Rockel P, Ninnemann H (2001) Role of nitric oxide synthase in the light-induced development of sporangiophores in Phycomyces blakesleeanus. Plant Phsyiology 126(3):13231330. https://doi:10.1104/pp.126.3.1323

52. Marcos AT, Ramos MS, Marcos JF, Carmona L, Strauss J, Cánovas D (2016) Nitric oxide synthesis by nitrate reductase is regulated during development in Aspergillus. Mol Microbiol 99(1):15-33. https://doi:10.1111/mmi.13211

53. Marcos AT, Ramos MS, Schinko T, Strauss J, Cánovas D (2020) Nitric oxide homeostasis is required for light-dependent regulation of conidiation in Aspergillus. Fungal Genet Biol 137:103337. https://doi:10.1016/j.fgb.2020.103337 
54. Mirabito PM, Adams TH, Timberlake WE (1989) Interactions of three sequentially expressed genes control temporal and spatial specificity in Aspergillus development. Cell 57(5):859-868. https://doi:10.1016/0092-8674(89)90800-3

55. Muñiz-Paredes F, Miranda-Hernández F, Loera 0 (2017) Production of conidia by entomopathogenic fungi: from inoculants to final quality tests. World J Microbiol Biotechnol 33(3):57. https://doi:10.1007/s11274-017-2229-2

56. Ni M, Yu JH (2007) A novel regulator couples sporogenesis and trehalose biogenesis in Aspergillus nidulans. PLoS One 2(10):e970. https://doi:10.1371/journal.pone.0000970

57. Nosanchuk JD, Casadevall A (2003) The contribution of melanin to microbial pathogenesis. Cell Microbiol 5(4):203-223. https://doi:10.1046/j.1462-5814.2003.00268.x

58. Ojeda-López M, Chen W, Eagle CE, Gutiérrez G, Jia WL, Swilaiman SS, Huang Z, Park HS, Yu JH, Cánovas D, Dyer PS (2018) Evolution of asexual and sexual reproduction in the aspergilli. Stud Mycol 91:37-59. https://doi:10.1016/j.simyco.2018.10.002

59. Pacelli C, Cassaro A, Maturilli A, Timperio AM, Gevi F, Cavalazzi B, Stefan M, Ghica D, Onofri S (2020) Multidisciplinary characterization of melanin pigments from the black fungus Cryomyces antarcticus. Appl Microbiol Biotechnol 104(14):6385-6395. https://doi:10.1007/s00253-020-106660

60. Pal AK, Gajjar DU, Vasavada AR (2014) DOPA and DHN pathway orchestrate melanin synthesis in Aspergillus species. Med Mycol 52(1):10-18. https://doi 10.3109/13693786.2013.826879

61. Papon N, Gangneux JP, Delneste Y (2020) Fungal melanin rewires macrophage metabolism. Trends Biochem Sci 45(9):728-730. http://doi: 10.1016/j.tibs.2020.06.006 https://doi:10.1016/j.tibs.2020.06.006

62. Park G, Pan S, Borkovich KA (2008) Mitogen-activated protein kinase cascade required for regulation of development and secondary metabolism in Neurospora crassa. Eukaryot Cell 7(12):2113-2122. https://doi:10.1128/EC.00466-07

63. Park HS, Yu JH (2012) Genetic control of asexual sporulation in filamentous fungi. Curr Opin Microbiol 15(6):669-677. https://doi:10.1016/j.mib.2012.09.006

64. Prats E, Carver TL, Mur LA (2008) Pathogen-derived nitric oxide influences formation of the appressorium infection structure in the phytopathogenic fungus Blumeria graminis. Res Microbiol 159(6):476-480. https://doi:10.1016/j.resmic.2008.04.001

65. Rőszer T (2012) The biology of subcellular nitric oxide. Springer Dordrecht, Heidelberg London. http://doi:10.1007/978-94-007-2819-6

66. Sanzhaeva U, Vorontsova Y, Glazachev Y, Slepneva I (2016) Dual effect of nitric oxide on phenoloxidase-mediated melanization. J Enzyme Inhib Med Chem 31(6):1063-1068. https://doi:10.3109/14756366.2015.1088843

67. Simmons EG (2001) Perfect states of Stemphylium-IV. Harvard Papers in Botany 6:199-208.

68. Thines $E$, Anke $H$, Weber RW (2004) Fungal secondary metabolites as inhibitors of infection-related morphogenesis in phytopathogenic fungi. Mycological Research 108(Pt1):14-25. 
https://doi:10.1017/s0953756203008943

69. Tomankova S, Abaffy P, Sindelka R (2017) The role of nitric oxide during embryonic epidermis development of Xenopus laevis. Biology Open 6(6):862-871. https://doi:10.1242/bio.023739

70. Trinetta V, Linton RH, Morgan MT (2013) Use of chlorine dioxide gas for the postharvest control of Alternaria alternata and Stemphylium vesicarium on Roma tomatoes. Journal of the Science of Food Agriculture 93(13):3330-3333. https://doi:10.1002/jsfa.6180

71. Valiante V, Baldin C, Hortschansky P, Jain R, Thywißen A, Straßburger M, Shelest E, Heinekamp T, Brakhage AA (2016) The Aspergillus fumigatus conidial melanin production is regulated by the bifunctional bHLH DevR and MADS-box RImA transcription factors. Mol Microbiol 102(2):321-335. https://doi:10.1111/mmi.13462

72. Vieira AL, Linares E, Augusto O, Gomes SL (2009) Evidence of aCa(2+)-(*)NO-cGMP signalingpathway controlling zoospore biogenesis in the aquatic fungus Blastocladiella emersonii. Fungal Genet Biol 46(8):575-584. https://doi:10.1016/j.fgb.2009.04.002

73. Wang J, Higgins VJ (2005) Nitric oxide has a regulatory effect in the germination of conidia of. Colletotrichum coccodes. Fungal Genet Biol 42(4):284-292. https://doi:10.1016/j.fgb.2004.12.006

74. Xiong D, Wang Y, Tian C (2015) Transcriptomic profiles of the smoke tree wilt fungus Verticillium. dahliae under nutrient starvation stresses. Mol Genet Genomics 290(5):1963-1977. https://doi:10.1007/s00438-015-1052-4

75. Yu X, Huo L, Liu H, Chen L, Wang Y, Zhu X (2015) Melanin is required for the formation of the multicellular conidia in the endophytic fungus Pestalotiopsis microspora. Microbiol Res 179:1-11. https://doi:10.1016/j.micres.2015.06.004

76. Zhao Y, Ding J, Yuan W, Huang J, Huang W, Wang Y, Zheng W (2017) Production of a fungal. furocoumarin by a polyketide synthase gene cluster confers the chemo-resistance of Neurospora crassa to the predation by fungivorous arthropods. Environ Microbiol 19(10):3920-3929. https://doi:10.1111/1462-2920.13791

77. Zhao Y, Lim J, Xu J, Yu JH, Zheng W (2020) Nitric oxide as a developmental and metabolic signal in filamentous fungi. Molecular Microbiology 113:872-882. https://doi:10.1111/mmi.14465

78. Zhao Y, Wang Q, Wang S, Liu X, Yu JH, Zheng W, Zhang X (2019) Disturbance in biosynthesis of arachidonic acid impairs the sexual development of the onion blight pathogen Stemphylium eturmiunum. Curr Genet 65(3):759-771. https://doi:10.1007/s00294-019-00930-w

79. Zhao Y, Xi Q, Xu Q, He M, Ding J, Dai Y, Keller NP, Zheng W (2015) Correlation of nitric oxide produced by an inducible nitric oxide synthase-like protein with enhanced expression of the phenylpropanoid pathway in Inonotus obliquus cocultured with Phellinus morii. Appl Microbiol Biotechnol 99(10):4361-4372. https://doi:10.1007/s00253-014-6367-2

\section{Figures}


A

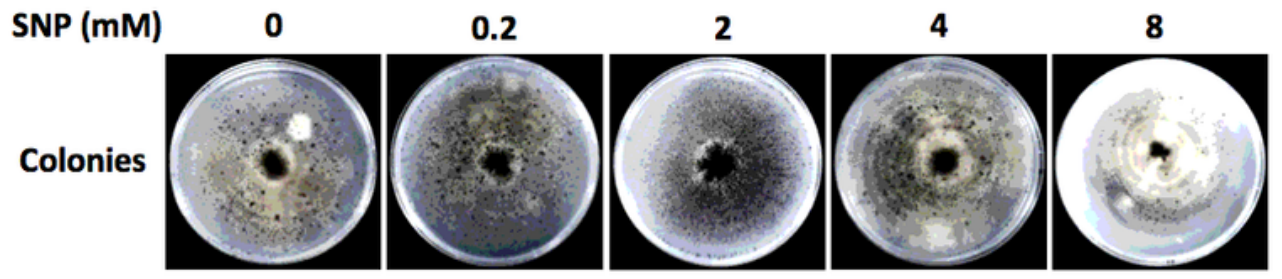

B

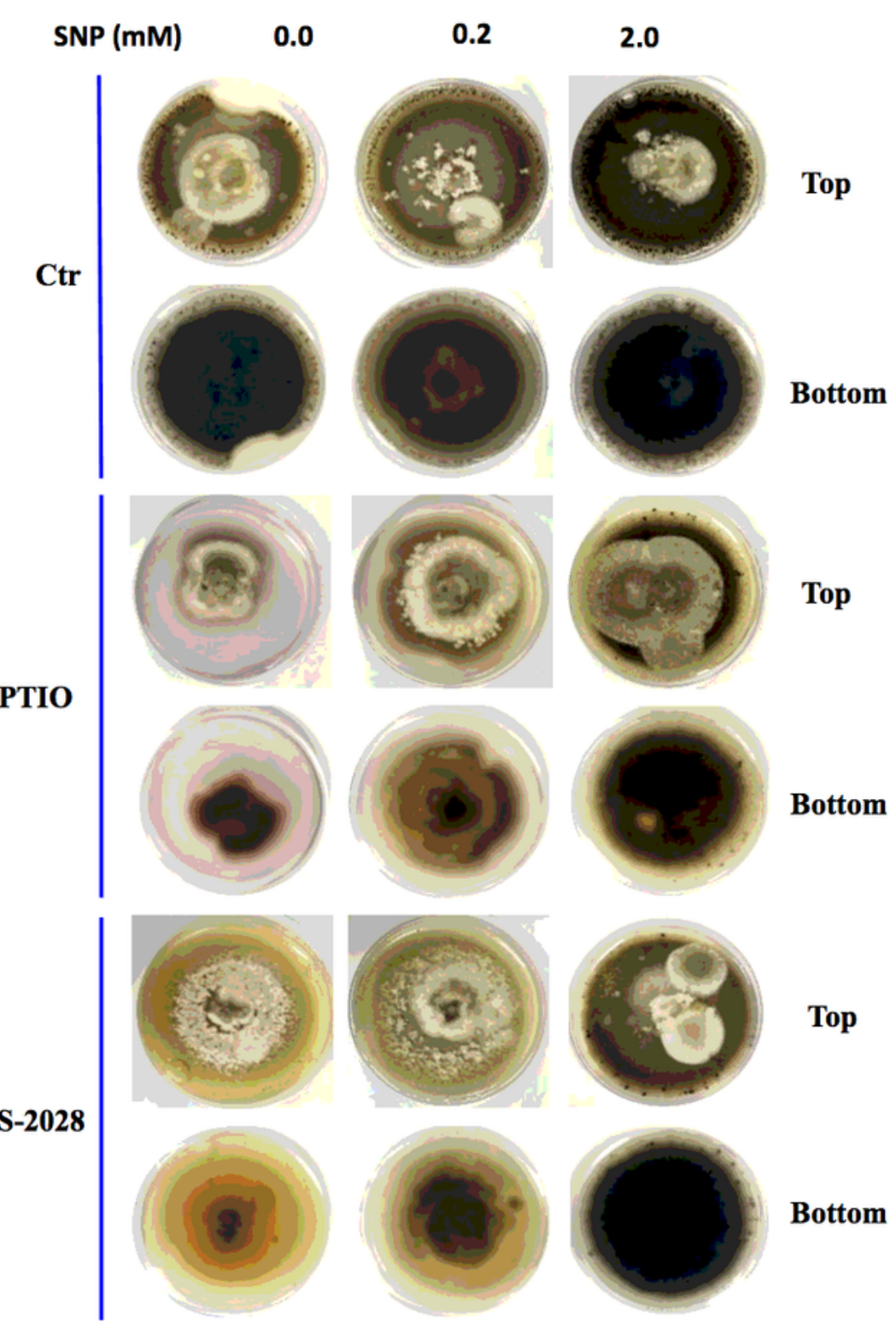

\section{Figure 1}

Effects of nitric oxide on growth and development of $S$. eturmiunum. (A) Changes in phenotype induced by SNP at concentrations of $0,0.2,2,4$ or $8 \mathrm{mmol} / \mathrm{L}$, respectively. (B) Changes in phenotype in the absence or presence of SNP $(0.2 \mathrm{mmol} / \mathrm{L}$ and $2 \mathrm{mmol} / \mathrm{L})$, CPTIO $(1 \mathrm{mmol} / \mathrm{L})$ or NS-2028 $(18 \mu \mathrm{mol} / \mathrm{L})$. SNP, sodium nitroprusside; CPTIO, arboxy-PTIO; NS-2028, inhibitor of sGC. 
A
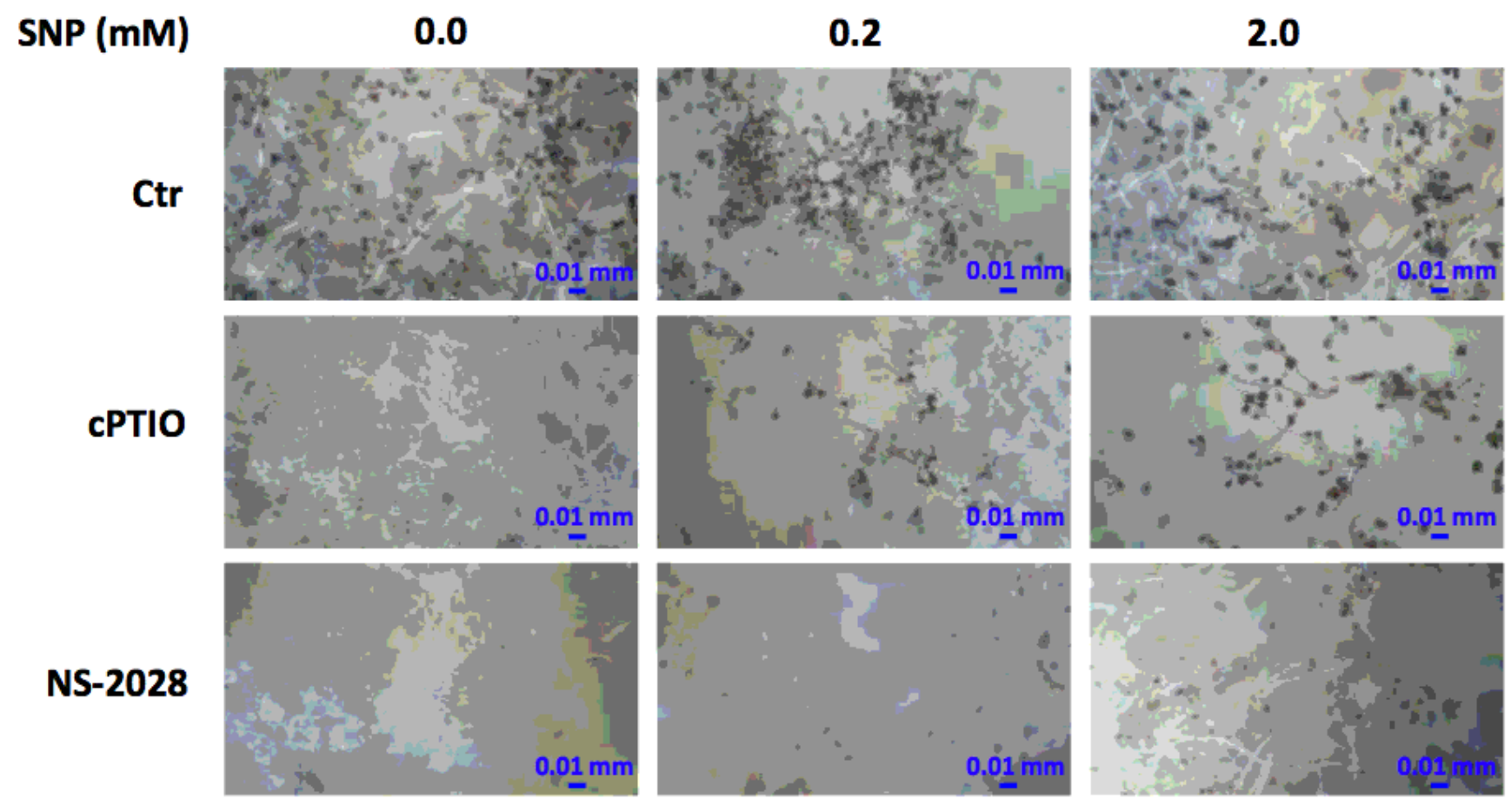

B
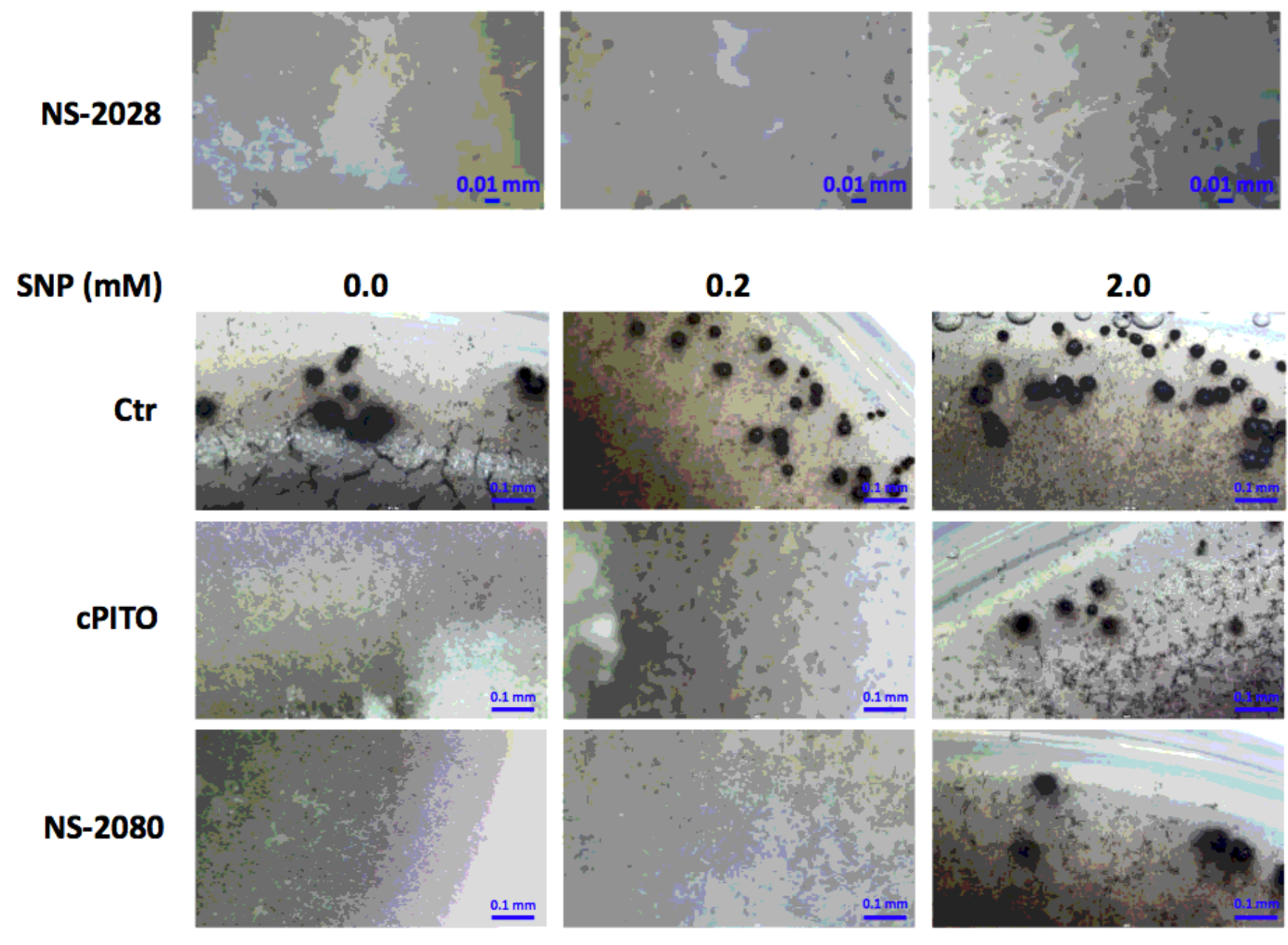

\section{Figure 2}

Propagules formation of S. eturmiunum in presence of SNP and/or NO scavenger and SGC inhibitor. (A) Conidia formation in the absence or presence of SNP at concentrations of 0.2 and $2 \mathrm{mmol} / \mathrm{L}$, or the presence of $\mathrm{CPTIO}$ at $1 \mathrm{mmol} / \mathrm{L}$ or NS-2028 at $18 \mu \mathrm{mol} / \mathrm{L}$. The blue bar $=0.01 \mathrm{~mm}$. (B) Pseudothecia formation in the absence or presence of SNP at concentrations of 0.2 and $2 \mathrm{mmol} / \mathrm{L}$, or the presence of 
cPTIO at $1 \mathrm{mmol} / \mathrm{L}$ or NS-2028 at $18 \mu \mathrm{mol} / \mathrm{L}$. The blue bar $=0.1 \mathrm{~mm}$. SNP, sodium nitroprusside; $\mathrm{cPTIO}$, carboxy-PTIO; NS-2028, sGC inhibitor.

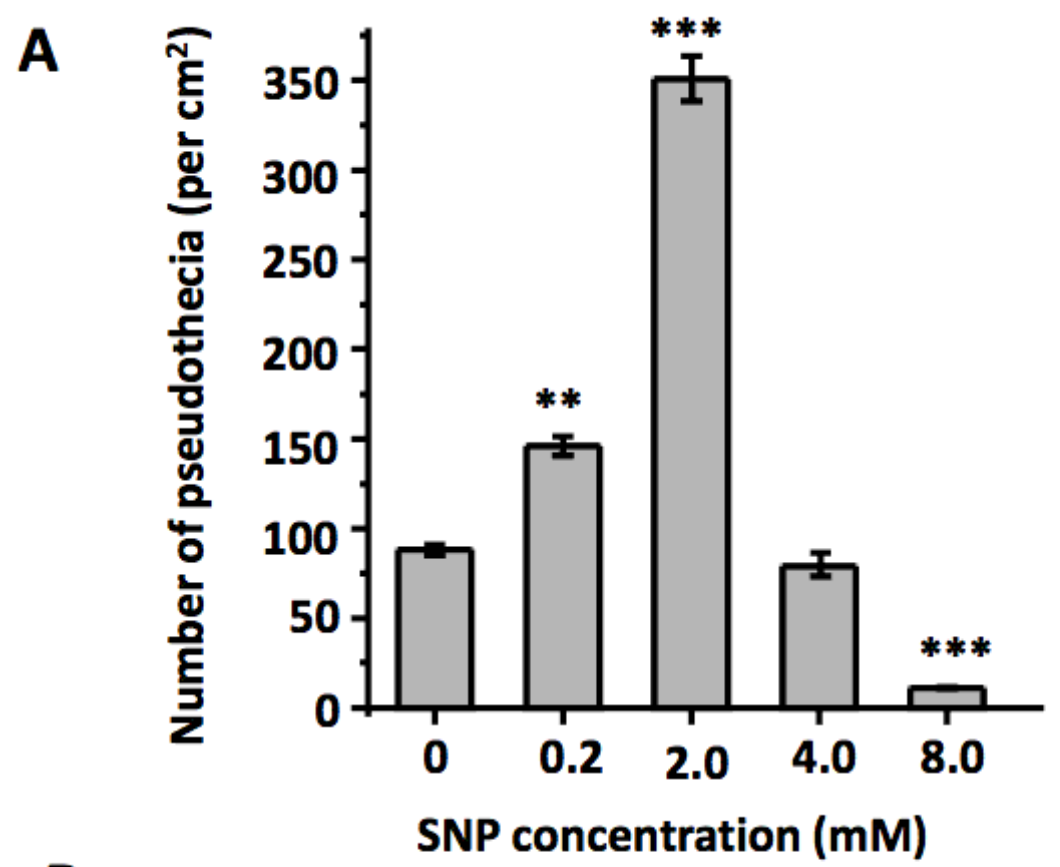

B
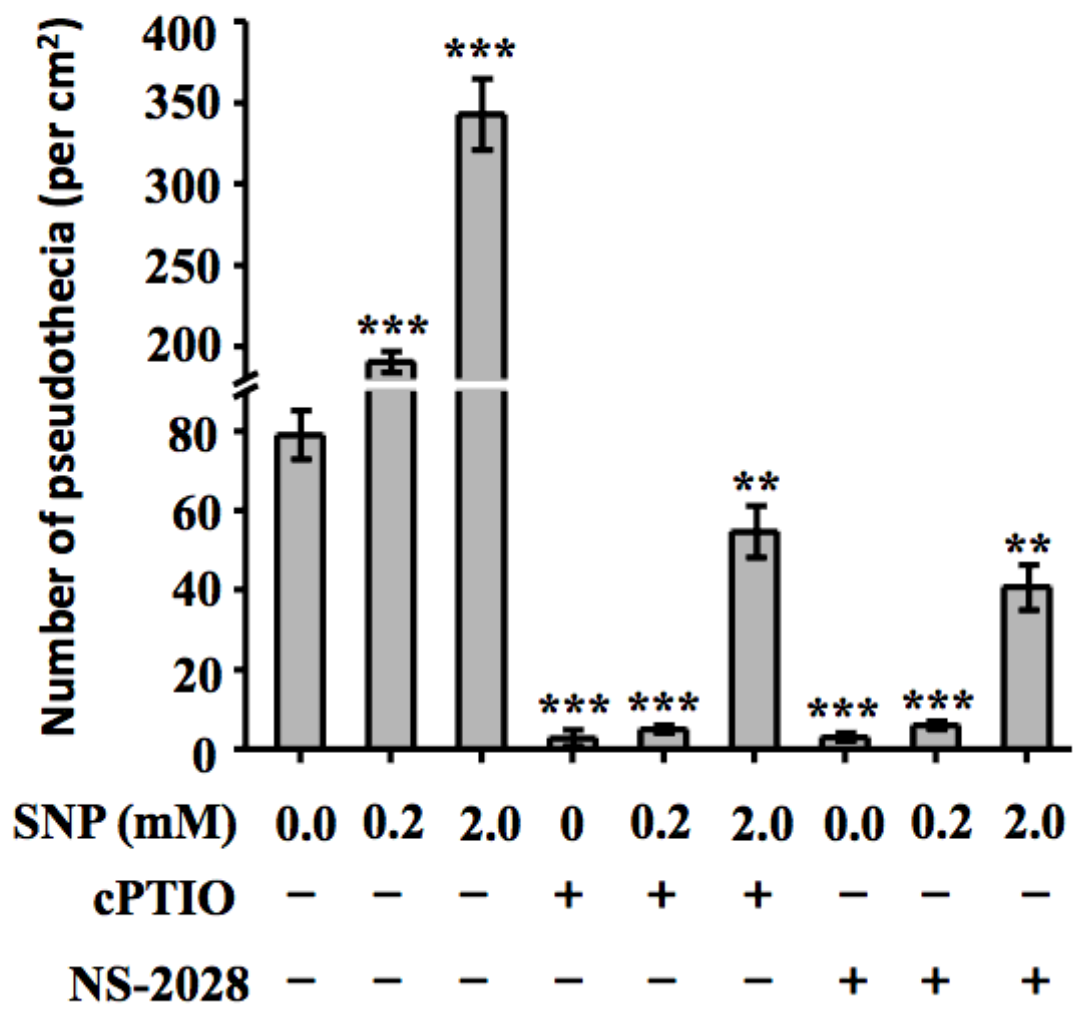

Figure 3

Effects of nitric oxide on pseudothecia formation in S. eturmiunum. (A) Numbers of pseudothecia induced by SNP at the concentrations of $0,0.2,2,4$ or $8 \mathrm{mmol} / \mathrm{L}$, respectively. (B) Numbers of pseudothecia in the cultures in the absence or presence of SNP at concentrations of 0.2 and $2 \mathrm{mmol} / \mathrm{L}$, or 
the presence of CPTIO at $1 \mathrm{mmol} / \mathrm{L}$ or NS-2028 at $18 \mu \mathrm{mol} / \mathrm{L}$. SNP, sodium nitroprusside; CPTIO, carboxyPTIO; NS-2028, inhibitor of SGC. Values are means \pm SD $(n=3)$, error bars represent $S D$. ${ }^{\star *} P<0.01$, $* \star \star$ $\mathrm{P}<0.001$ by $t$ test.

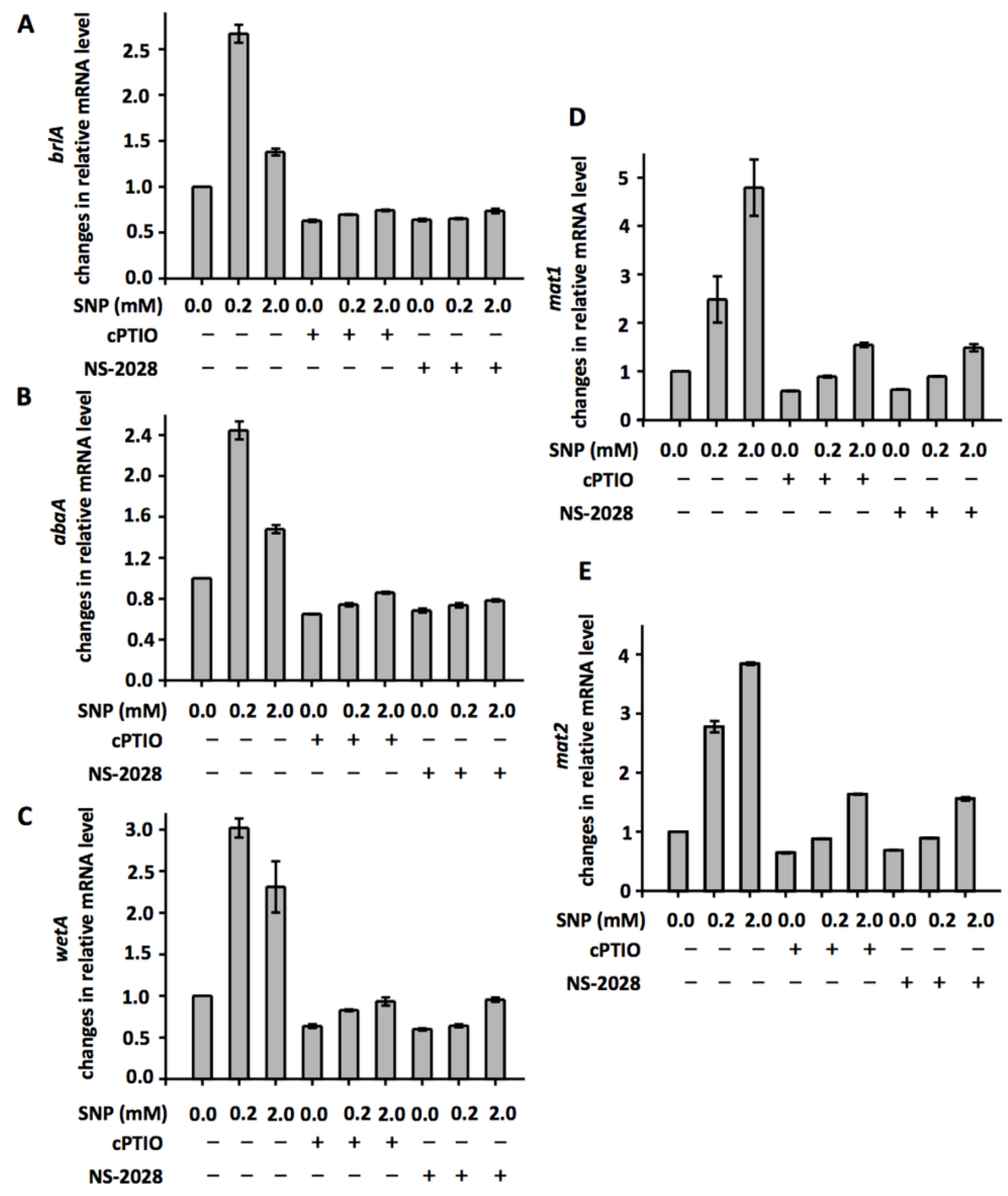

Figure 4

Changes in expression of genes involved in asexual and sexual development in $\mathrm{S}$. eturmiunum. (A) Relative expression levels of brlA. (B) Relative expression levels of abaA. (C) Relative expression levels of 
wetA. (D) Relative expression levels of mat1. (E) Relative expression levels of mat2. Actin was used as internal reference. Data are the average of at least three independent experiments, and err bars are the standard error of the mean.

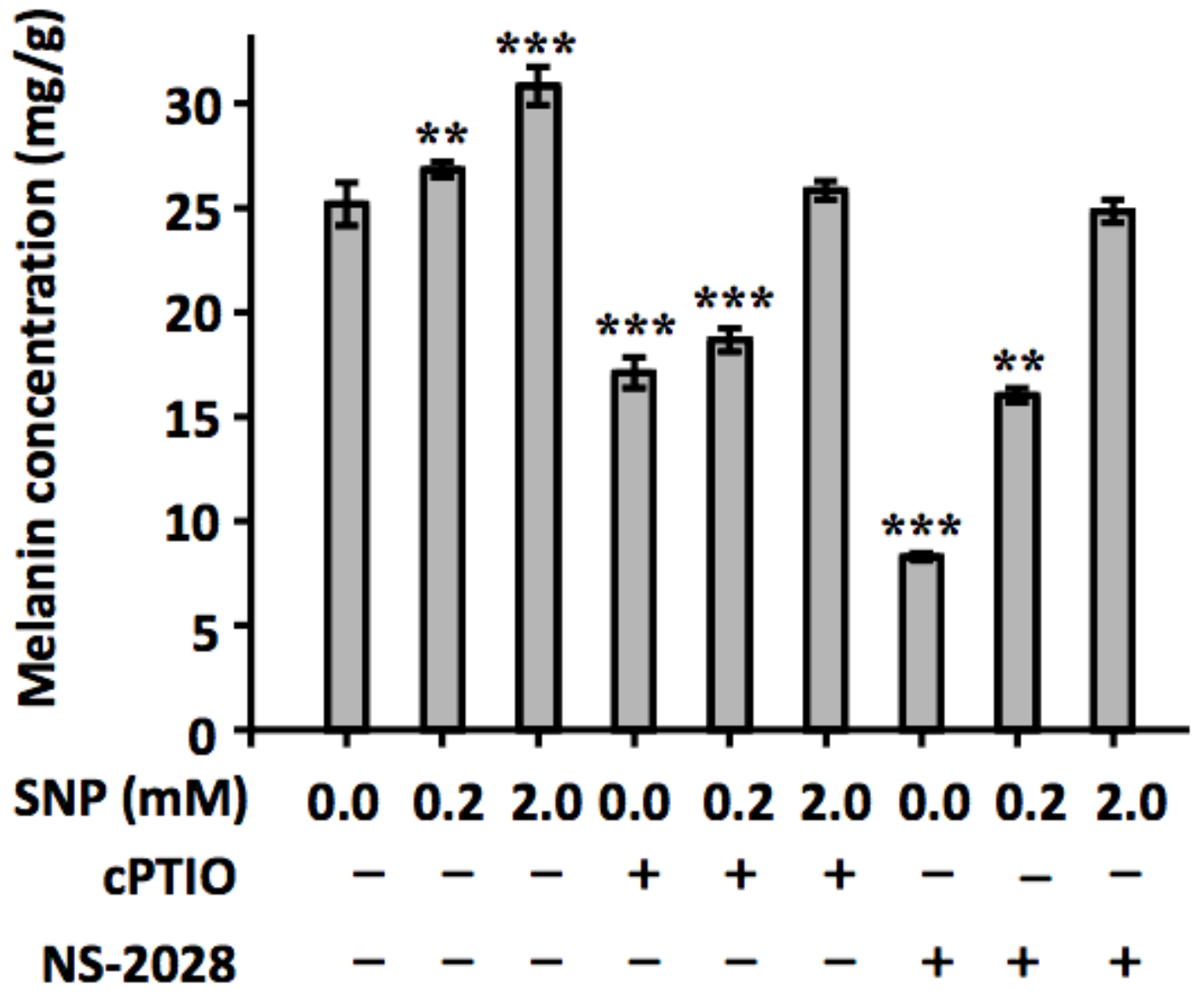

Figure 5

Accumulation of melanin in absence or presence of SNP, or simultaneously with cPTIO or NS-2028. SNP at 0.2 or $2 \mathrm{mmol} / \mathrm{L}, \mathrm{CPTIO}$ at $1 \mathrm{mmol} / \mathrm{L}$, NS-2028 at $18 \mu \mathrm{mol} / \mathrm{L}$. SNP, sodium nitroprusside; CPTIO, carboxy-PTIO; NS-2028, inhibitor of SGC. Values are means \pm SD $(n=3)$, error bars represent SD. ${ }^{*} P<0.01$, $\star \star \star P<0.001$ by $t$ test. 
A

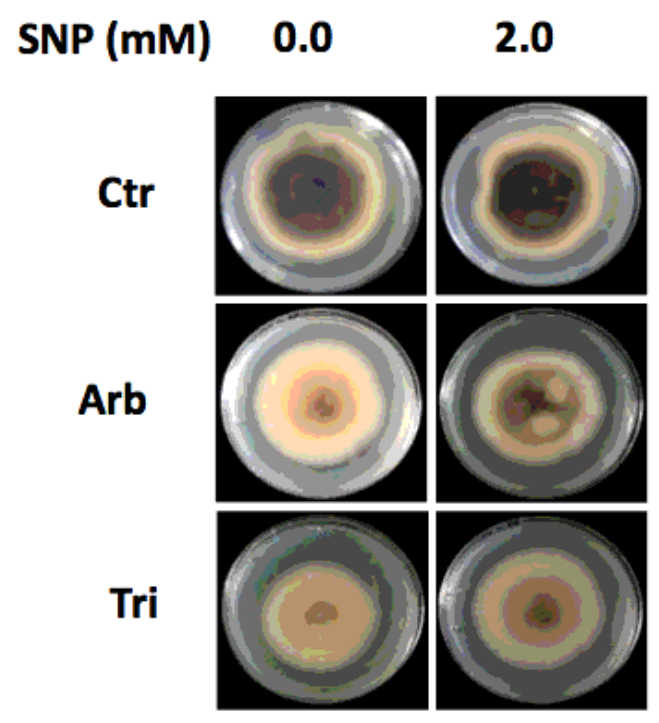

C

SNP (mM)

0.0

Ctr

Arb

Tri
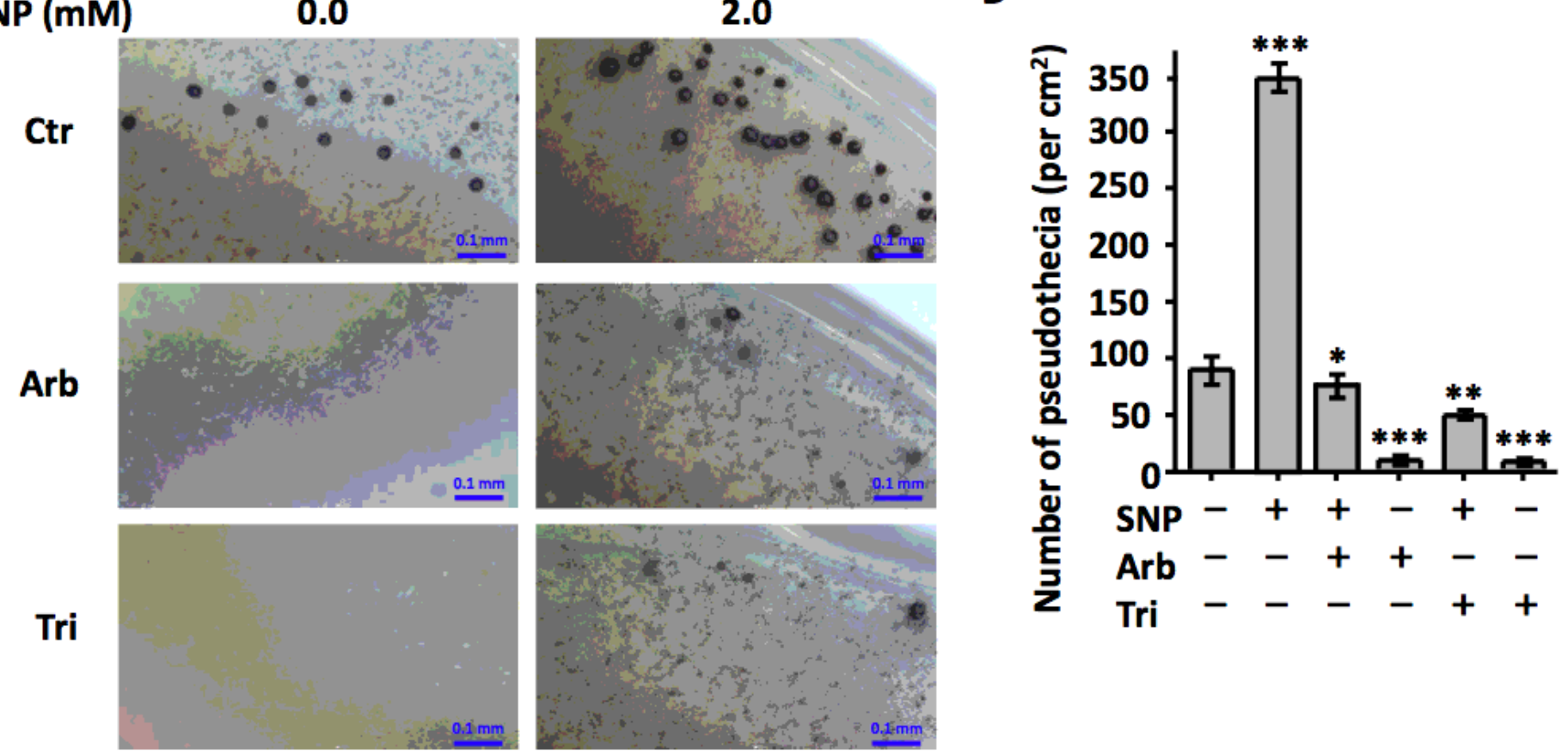

B
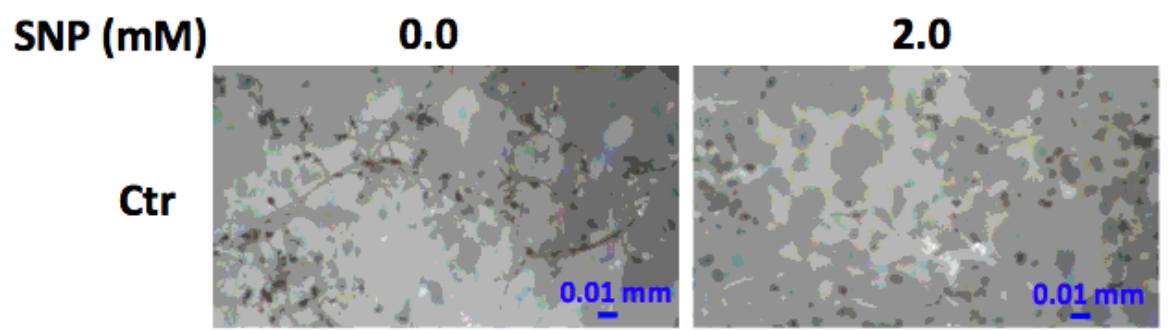

Arb
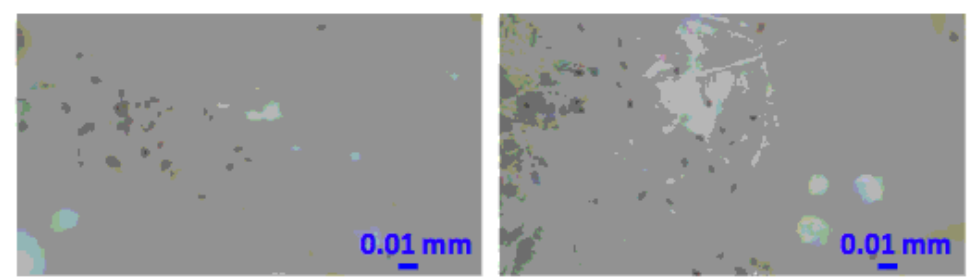

Tri
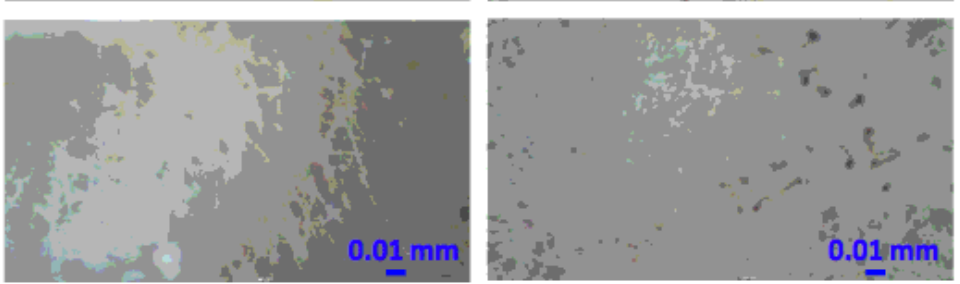

Figure 6

Correlation between melanin biosynthesis and propagules formation in presence of SNP and/or arbutin and tricyclazole. (A) Changes in phenotype. (B) Conidia formation. The blue bar $=0.01 \mathrm{~mm}$. (C) Pseudothecia formation. The blue bar $=0.1 \mathrm{~mm}$. (D) Numbers of pseudothecia. SNP at $2 \mathrm{mmol} / \mathrm{L}$, arbutin at $30 \mathrm{mg} / \mathrm{L}$, tricyclazole at $30 \mathrm{mg} / \mathrm{L}$. SNP, sodium nitroprusside; Arb, arbutin; Tri, tricyclazole. Values are means $\pm S D(n=3)$, error bars represent $S D$. ${ }^{*} P<0.05$, $* \star P<0.01$, $* \star \star ~ P<0.001$ by $t$ test. 


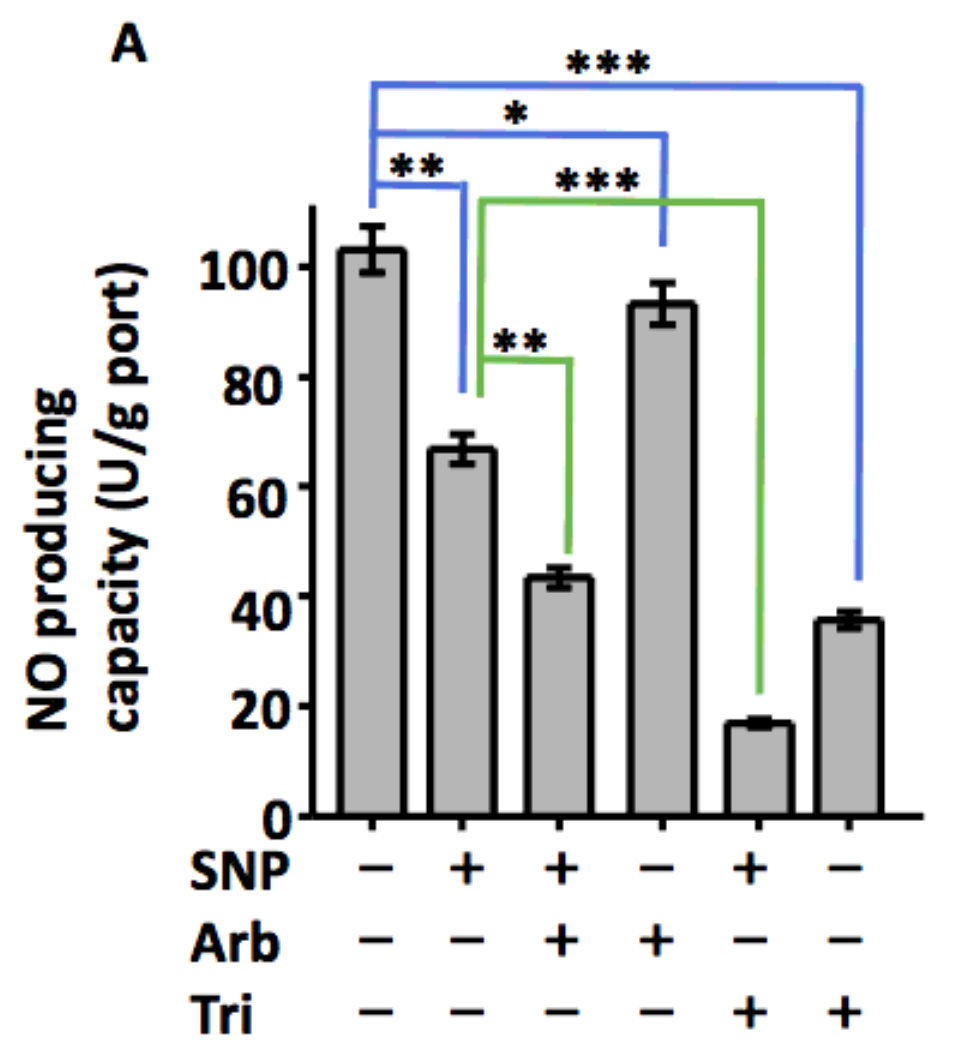

B
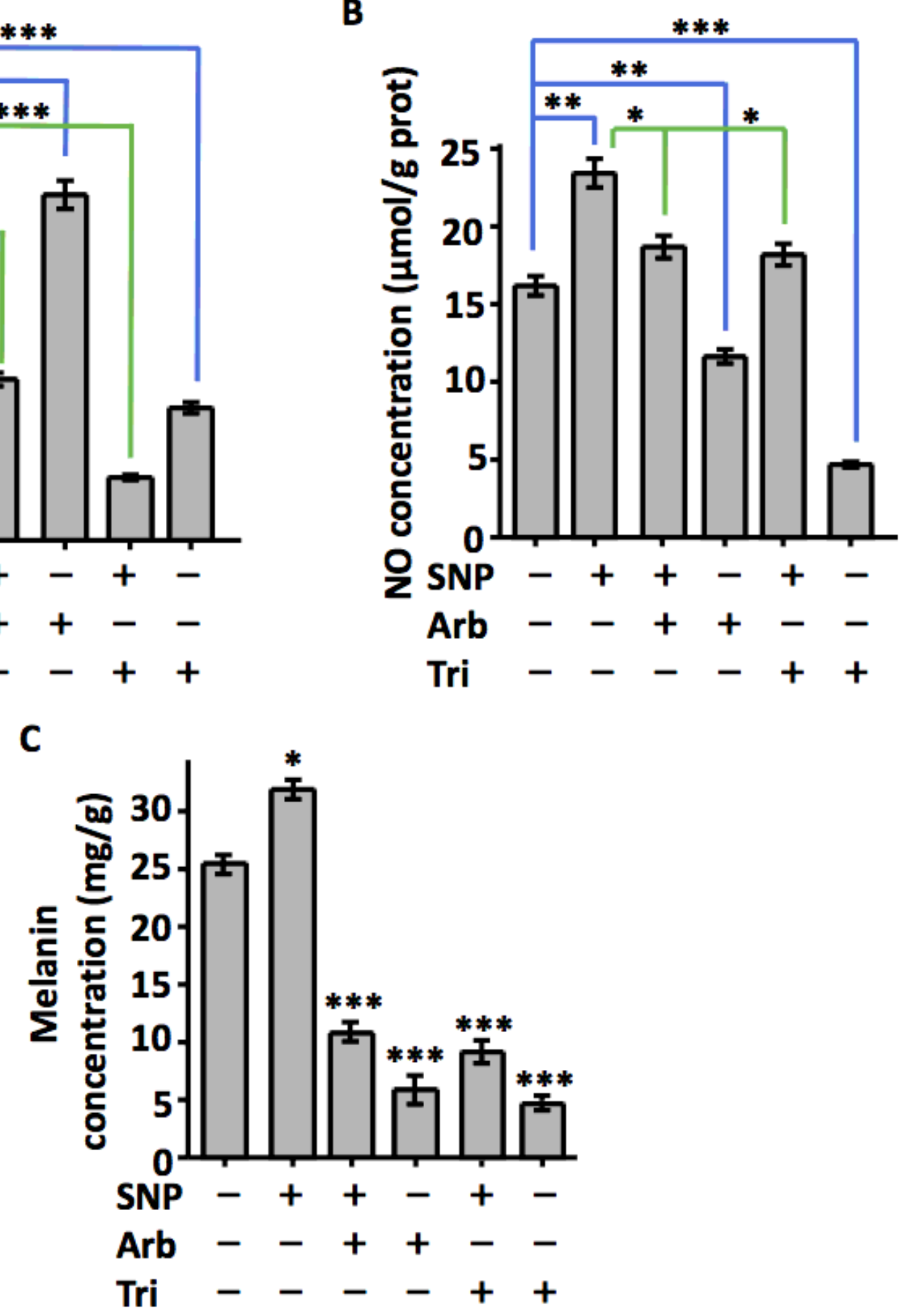

Figure 7

Effect of SNP and/or melanin synthesis inhibitors on NO and melanin production in S. eturmiunum. (A) NO producing capacity in the absence or presence of SNP $(2 \mathrm{mmol} / \mathrm{L})$, arbutin $(30 \mathrm{mg} / \mathrm{L})$ or tricyclazole $(30 \mathrm{mg} / \mathrm{L})$. (B) Concentration of NO in the absence or presence of SNP $(2 \mathrm{mmol} / \mathrm{L})$, arbutin $(30 \mathrm{mg} / \mathrm{L})$ or tricyclazole $(30 \mathrm{mg} / \mathrm{L})$. (C) Accumulation of melanin in the absence or presence of SNP $(2 \mathrm{mmol} / \mathrm{L})$, 
arbutin (30 mg/L) or tricyclazole (30 mg/L). SNP, sodium nitroprusside; Arb, arbutin; Tri, tricyclazole. Values are means $\pm S D(n=3)$, error bars represent $S D$. ${ }^{*} P<0.05$, ** $P<0.01$, *** $P<0.001$ by $t$ test.

A

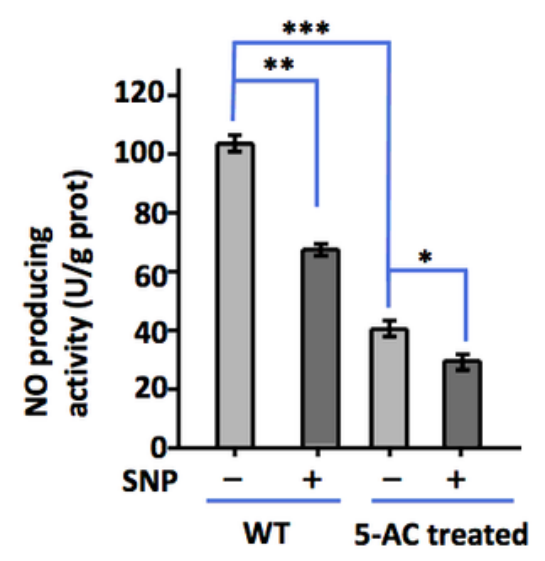

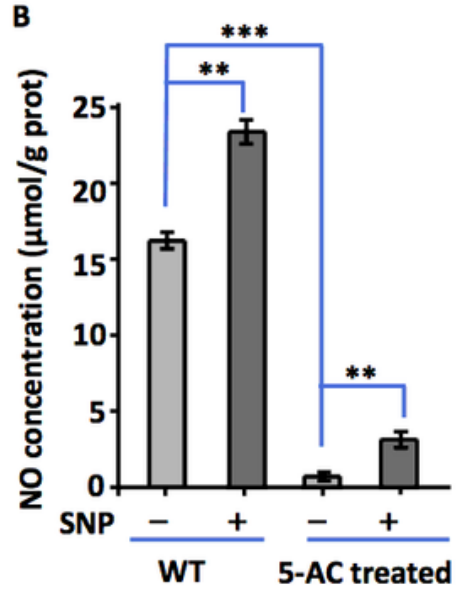

C

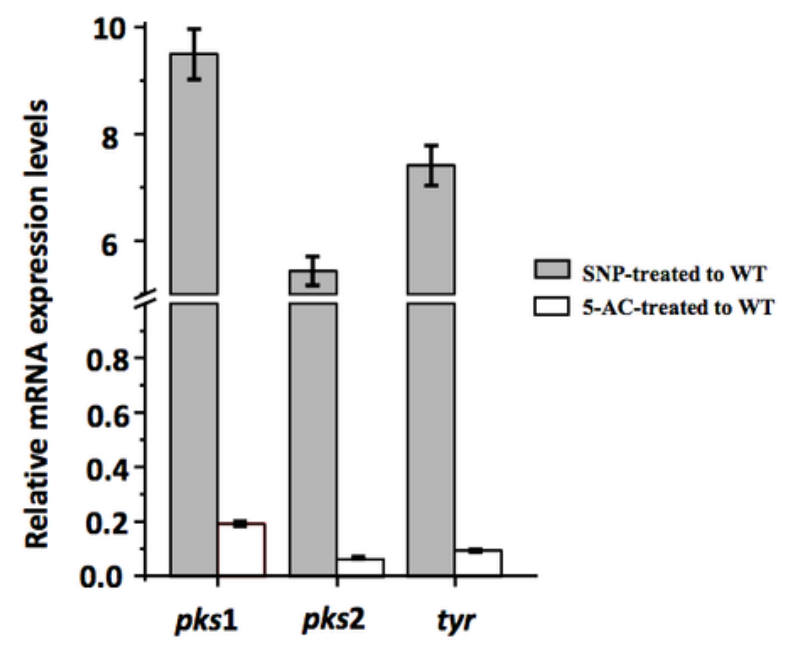

D

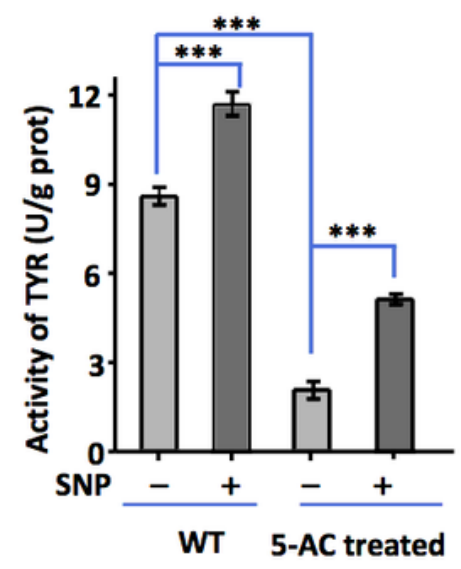

E

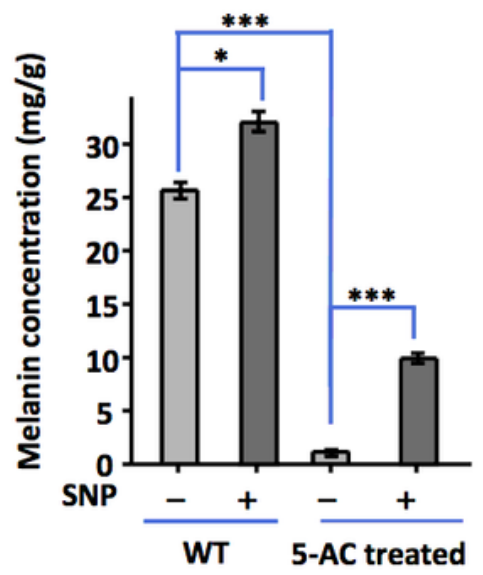

Figure 8

Effect of SNP on NO and melanin formation in wild-type and 5-AC treated S. eturmiunum. (A) Effect of SNP (2 mmol/L) on NO producing capacity. (B) NO concentration in wild type and 5-AC treated S. eturmiunum induced by SNP ( $2 \mathrm{mmol} / \mathrm{L})$. (C) Relative mRNA expression levels of pks and tyr related to 
the melanin synthase in the wild type and 5-AC treated S. eturmiunum (D) Tyrosinase activity in wild type and 5-AC treated S. eturmiunum. (E) SNP (2 mmol/L) induced changes in melanin accumulation. SNP, sodium nitroprusside. Actin was used as internal reference. Values are means $\pm S D(n=3)$, error bars represent $S D$. ${ }^{*} P<0.05$, ** $P<0.01$, *** $P<0.001$ by $t$ test.

A

LO8030

pryG control
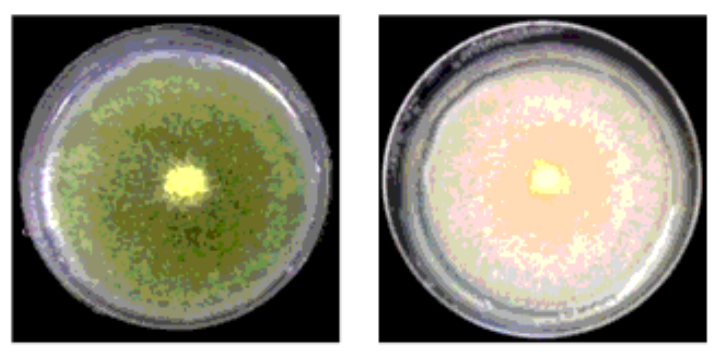

HEpks1

HEpks2
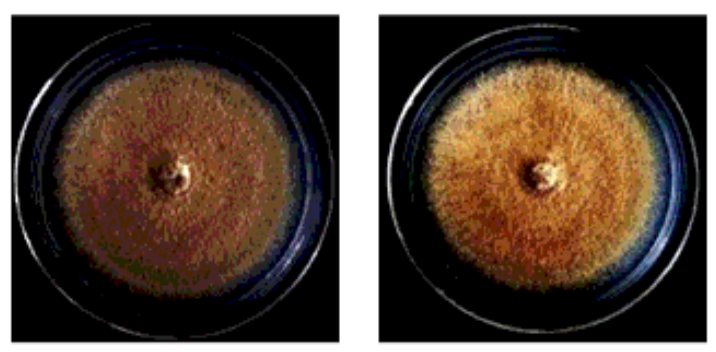

B

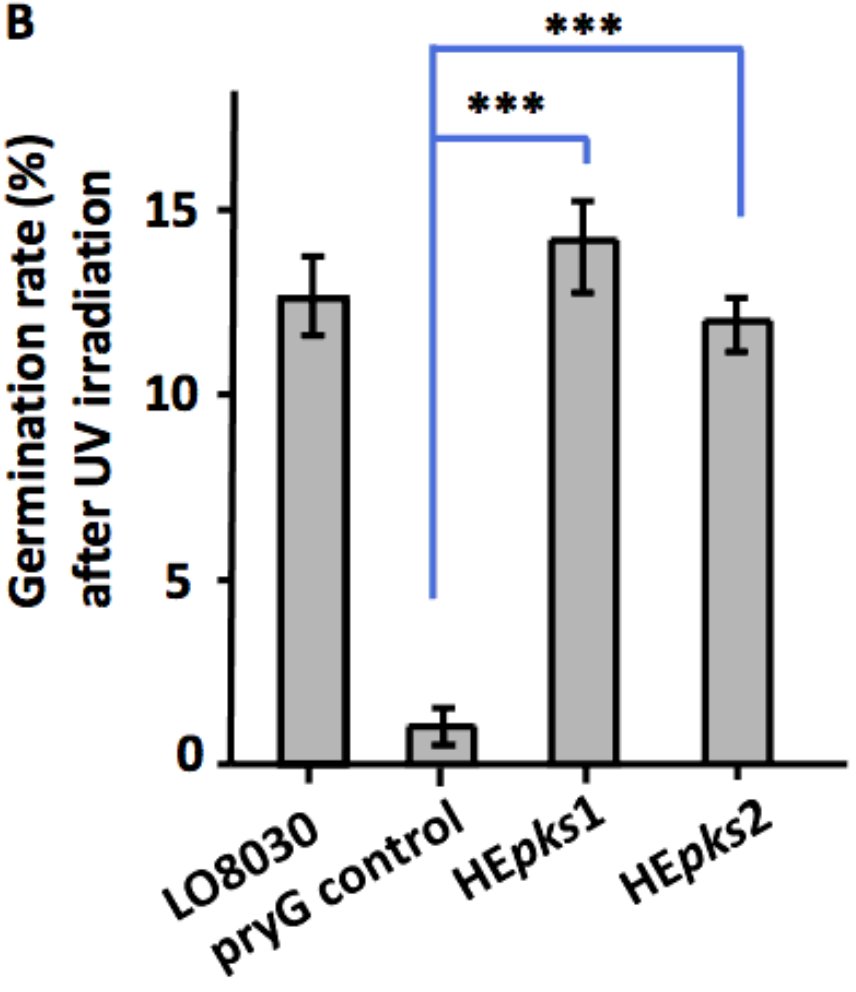

Figure 9 
Heterologous expression of pks and resistance of the conidia in the transformants against UV irradiation. (A) The genes encoding PKS1 and PKS2 are responsible for producing the dark-brown pigments. (B) Conidia germination upon exposure to UV irradiation. The conidia were irradiated by UV ( $30 \mathrm{~W})$ at a distance of $65 \mathrm{~cm}$ for $15 \mathrm{~min}$. L08030: Aspergillus nidulans L08030; pyrG control: pyrG related wA in A. nidulans L08030; HEpks1: heterologous expression of pks1 in host strain A. nidulans L08030; HEpks2: heterologous expression of pks2 in host strain A. nidulans L08030. Results are means $\pm S D(n=3)$, error bars represent $S D$. $* \star \star ~ P<0.001$ by $t$ test.

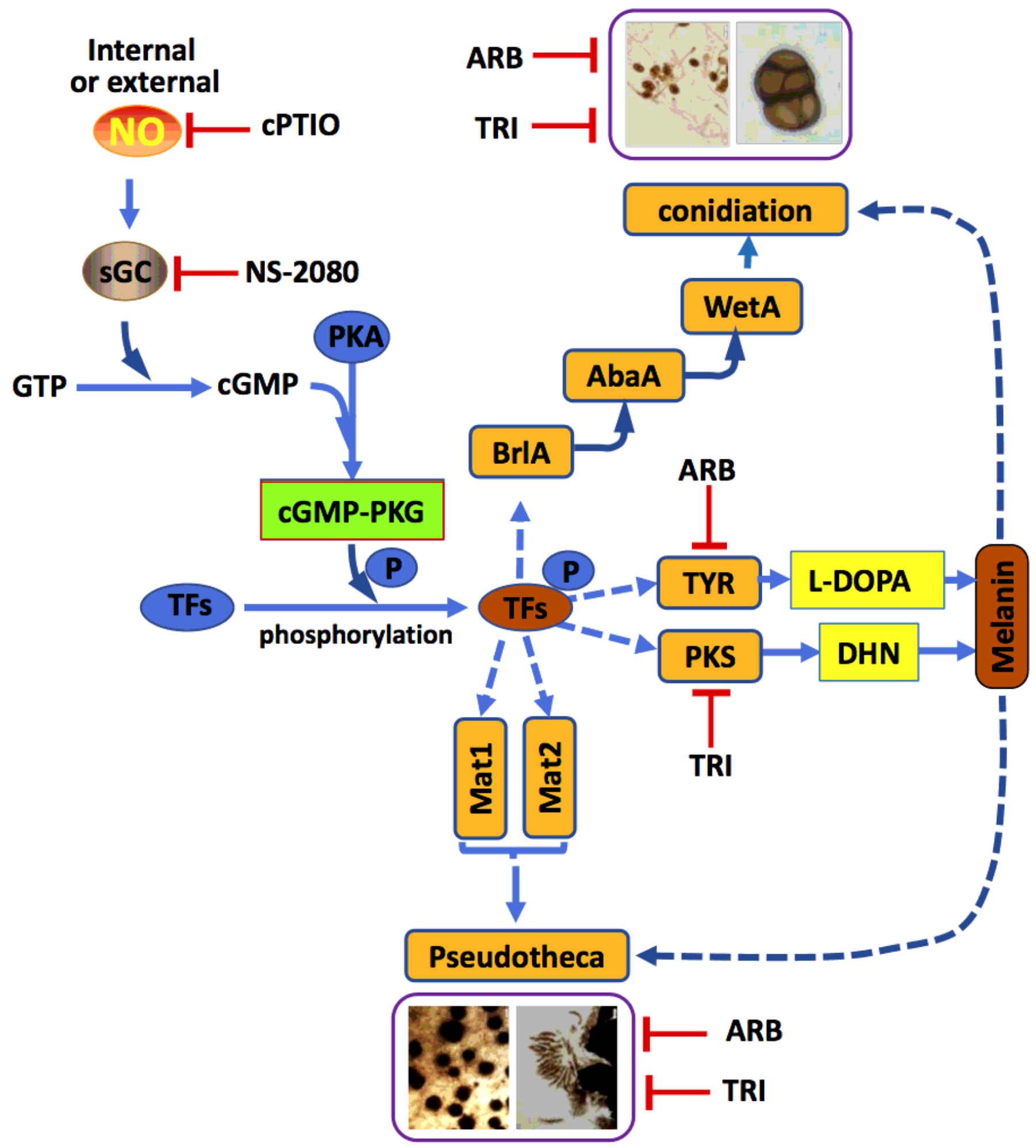


Figure 10

The proposed mechanism mediated by NO in propagules formation and melanins production in $\mathrm{S}$. eturmiunum. DHN, dihydroxynaphthalene pathway; DOPA, 3,4-dihydroxyphenylalanine pathway; NO, nitric oxide; PKS, polyketide synthase; SNP, sodium nitroprusside; TYR, tyrosinase; CPTIO, carboxy-PTIO; NS2028, inhibitor of sGC; Arb, arbutin; Tri, tricyclazole. 